\title{
Retrochalcone derivatives
}

are positive allosteric

modulators at synaptic

and extrasynaptic $\mathrm{GABA}_{\mathrm{A}}$

receptors in vitro

Ruotian Jiang ${ }^{1}$, Akiko Miyamoto ${ }^{2}$, Adeline Martz ${ }^{1}$, Alexandre Specht ${ }^{3}$, Hitoshi Ishibashi ${ }^{2}$, Marie Kueny-Stotz ${ }^{4}$, Stefan Chassaing ${ }^{4}$, Raymond Brouillard ${ }^{4}$, Lia Prado de Carvalho ${ }^{1}$, Maurice Goeldner ${ }^{3}$, Junichi Nabekura ${ }^{2}$, Mogens Nielsen ${ }^{5}$ and Thomas Grutter ${ }^{1}$

${ }^{1}$ Laboratoire de Biophysicochimie des Récepteurs Canaux, UMR 7199 CNRS, Conception et Application de Molécules Bioactives, Faculté de Pharmacie, Université de Strasbourg, Illkirch, France, ${ }^{2}$ Department of Developmental Physiology, National Institute for Physiological Sciences, Okazaki, Japan, ${ }^{3}$ Laboratoire de Chimie Bioorganique, UMR 7199 CNRS, Conception et Application de Molécules Bioactives, Faculté de Pharmacie, Université de Strasbourg, Illkirch, France, ${ }^{4}$ Laboratoire de Chimie des Polyphénols, UMR 7177 CNRS, Institut Le Bel, Université de Strasbourg, Strasbourg, France, and ${ }^{5}$ University of Copenhagen, Faculty of Pharmaceutical Sciences, Copenhagen, Denmark

\section{Correspondence}

Thomas Grutter, Laboratoire de Biophysicochimie des Récepteurs Canaux, UMR 7199 CNRS, Conception et Application de Molécules Bioactives, Faculté de Pharmacie, Université de Strasbourg, 67400 Illkirch, France. E-mail: grutter@bioorga.u-strasbg.fr

This work was supported by ANR (06-0050-01) and CNRS (PIME) to T. G., and by Grant-in-Aid for Scientific Research of Japan (18077009 to J. N., 21600019 to H. I.). R. J. is a recipient of fellowship from the China Scholarship Council.

\section{Keywords}

GABAA ion channels; trans-retrochalcones; allosteric modulators; flavylium salts

\section{Received}

29 June 2010

Revised

10 September 2010

Accepted

29 October 2010

\section{BACKGROUND AND PURPOSE}

Flavonoids, important plant pigments, have been shown to allosterically modulate brain $G A B A_{A}$ receptors $\left(G A B A_{A} R s\right)$. We previously reported that trans-6,4'-dimethoxyretrochalcone (Rc-OMe), a hydrolytic derivative of the corresponding flavylium salt, displayed nanomolar affinity for the benzodiazepine binding site of $G A B A_{A} R s$. Here, we evaluate the functional modulations of Rc-OMe, along with two other synthetic derivatives trans-6-bromo-4'-methoxyretrochalcone (Rc-Br) and $4,3^{\prime}$-dimethoxychalcone (Ch-OMe) on $\mathrm{GABA}_{A}$ Rs.

\section{EXPERIMENTAL APPROACH}

Whole-cell patch-clamp recordings were made to determine the effects of these derivatives on GABA $A_{A} R s$ expressed in HEK-293 cells and in hippocampal CA1 pyramidal and thalamic neurones from rat brain.

\section{KEY RESULTS}

Rc-OMe strongly potentiated GABA-evoked currents at recombinant $\alpha_{1-4} \beta_{2} \gamma_{2 s}$ and $\alpha_{4} \beta_{3} \delta$ receptors but much less at $\alpha_{1} \beta_{2}$ and $\alpha_{4} \beta_{3}$. Rc-Br and Ch-OMe potentiated GABA-evoked currents at $\alpha_{1} \beta_{2} \gamma_{25}$. The potentiation by Rc-OMe was only reduced at $\alpha_{1} H 101 R \beta_{2} \gamma_{2 s}$ and $\alpha_{1} \beta_{2} N 265 S \gamma_{2 s}$, mutations known to abolish the potentiation by diazepam and loreclezole respectively. The modulation of Rc-OMe and pentobarbital as well as by Rc-OMe and the neurosteroid 3 $\alpha, 21$-dihydroxy-5 $\alpha$-pregnan-20-one was supra-additive. Rc-OMe modulation exhibited no apparent voltage-dependence, but was markedly dependent on GABA concentration. In neurones, $\mathrm{Rc}-\mathrm{Br}$ slowed the decay of spontaneous inhibitory postsynaptic currents and both Rc-OMe and $\mathrm{Rc}-\mathrm{Br}$ positively modulated synaptic and extrasynaptic diazepam-insensitive GABA $\mathrm{A}_{A} \mathrm{Rs}$.

\section{CONCLUSIONS AND IMPLICATIONS}

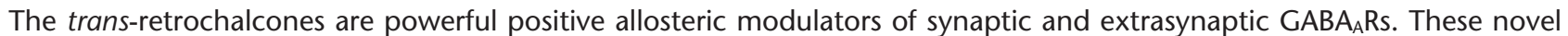
modulators act through an original mode, thus making them putative drug candidates in the treatment of $G A B A_{A}$-related disorders in vivo. 


\section{Abbreviations}

$\mathrm{BDZ}$, benzodiazepine; Ch-OMe, 4,3'-dimethoxychalcone; $\mathrm{GABA}_{\mathrm{A}} \mathrm{R}, \boldsymbol{\gamma}$-aminobutyric acid type A receptor; HEK, human embryonic kidney; IPSCs, inhibitory postsynaptic currents; Rc-Br, trans-6-bromo-4'-methoxyretrochalcone; Rc-OMe, trans-6,4'-dimethoxyretrochalcone; THDOC, 3 $\alpha, 21$-dihydroxy-5 $\alpha$-pregnan-20-one; THIP, 4,5,6,7-tetrahydroisoxazolo[5,4-c]pyridin-3(2H)-one; wt, wild type

\section{Introduction}

The $\gamma$-aminobutyric acid type $\mathrm{A}\left(\mathrm{GABA}_{\mathrm{A}}\right)$ receptor is the main inhibitory ligand-gated chloride channel in the brain. The receptor is the target for a wide range of important therapeutic agents, including benzodiazepines (BDZs), general anaesthetics and neurosteroids (D'Hulst et al., 2009; Olsen and Sieghart, 2009). $\mathrm{GABA}_{\mathrm{A}}$ receptors are comprised of a heteropentameric assembly of distinct subunits, for which the most prevalent form mediating the majority of fast synaptic inhibition in the adult mammalian brain consists of an $\alpha \beta \gamma$ subunit combination (Fritschy et al., 1992; Somogyi et al., 1996). On the other hand, receptor subtypes comprised of $\alpha \beta \delta$ subunits that play a key role in mediating tonic inhibition (Semyanov et al., 2004; Glykys and Mody, 2007) are extrasynaptically located and are also targets for endogenous neuroactive steroids (Belelli and Lambert, 2005) and ethanol (Jia et al., 2008).

Flavonoids are natural substances found in vascular plants (Harborne and Williams, 2000) and display a wide range of biological activities from anxiolytic (Griebel et al., 1999) to anti-inflammatory and analgesic effects (Heidari et al., 2009). It has been known since the late 1980s that this family of compounds acts at $\mathrm{GABA}_{\mathrm{A}}$ receptors (Nielsen et al., 1988). The ability of these compounds to compete with radiolabelled BDZs in rat and bovine brain tissues and to exhibit anxiolytic activity in rodents, suggests that these compounds mediate their activities through the $\mathrm{BDZ}$ site at $\mathrm{GABA}_{\mathrm{A}}$ receptors. However, subsequent studies have demonstrated that the compounds modulate $\mathrm{GABA}_{\mathrm{A}}$ receptors at a site independent of the high-affinity classical BDZ binding site (Hall et al., 2004; Hansen et al., 2005; Fernandez et al., 2008), indicating that this new family of compounds may exert their action through a novel, yet unidentified, binding site.

We have recently found that a series of flavylium salts also display binding displacement of the radiolabelled BDZ ligand Ro15-1788 in rat cortical membranes in vitro (Kueny-Stotz et al., 2008). More precisely, it is not the flavylium salts per se that exhibit binding activities but their corresponding hydrolytic trans-retrochalcones products, through an in vitro chemical transformation (Kueny-Stotz et al., 2008) (Figure 1A). One of these substituted trans-retrochalcones, namely trans-6,4'dimethoxyretrochalcone (Rc-OMe; see Figure 1B for chemical structure), displays nanomolar affinity for the $\mathrm{BDZ}$ binding site of brain $\mathrm{GABA}_{\mathrm{A}}$ receptors (Kueny-Stotz et al., 2008), leading to the attractive hypothesis that flavylium salts could be used as convenient precursors of trans-retrochalcones when dissolved in neutral buffers, resulting in a possible delayed action at $\mathrm{GABA}_{\mathrm{A}}$ receptors in vivo.

In this paper, we extend the characterization of Rc-OMe and two other substituted derivatives at $\mathrm{GABA}_{\mathrm{A}}$ receptors expressed in human embryonic kidney (HEK)-293 cells and in neurones from thalamus and hippocampus in vitro. We report that the trans-retrochalcones positively modulate $\mathrm{GABA}_{\mathrm{A}}$ receptors at a novel site distinct not only from the classical
A

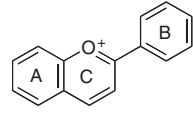

Flavylium salt

B<smiles>COc1ccc(C(C)=O)cc1</smiles>
$\mathrm{MeOH}$ RT $4 \mathrm{~h}$ $\rho=60-70 \%$<smiles>COc1ccc(C(=O)/C=C/c2ccccc2)cc1</smiles>
Rc-OMe: $\mathrm{R}^{1}=\mathrm{OMe}, \mathrm{R}^{2}=\mathrm{OH}$ Ch-OMe: $\mathrm{R}^{1}=\mathrm{OMe}, \mathrm{R}^{2}=\mathrm{H}$ Rc-Br: $\quad \mathrm{R}^{1}=\mathrm{Br}, \mathrm{R}^{2}=\mathrm{OH}$

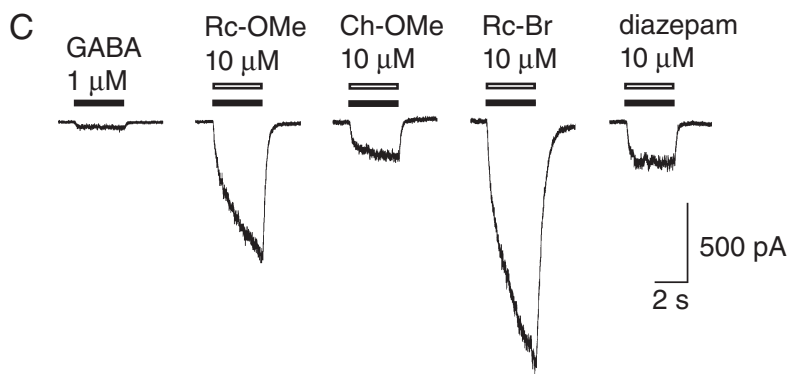

Figure 1

$\mathrm{Rc}-\mathrm{OMe}, \mathrm{Rc}-\mathrm{Br}$ and $\mathrm{Ch}$-OMe are positive modulators at recombinant $\alpha_{1} \beta_{2} \gamma_{2 s}$ receptor. (A) Hydrolysis of flavylium derivatives leads to the corresponding trans-retrochalcones (Kueny-Stotz et al., 2008). (B) Condensation step for synthesis of Rc-OMe, $\mathrm{Rc}-\mathrm{Br}$ and Ch-OMe. (C) Examples of current traces showing potentiations of GABA-elicited currents induced by $\mathrm{Rc}-\mathrm{OMe}, \mathrm{Rc}-\mathrm{Br}$, Ch-OMe and diazepam at recombinant $\alpha_{1} \beta_{2} \gamma_{2 s}$ receptors expressed in HEK-293 cells. Currents were recorded in the same cell separated by $\sim 30 \mathrm{~s}$ washout. Ch-OMe, 4,3'-dimethoxychalcone; HEK, human embryonic kidney; Rc-Br, trans-6-bromo-4'-methoxyretrochalcone; Rc-OMe, trans-6, $4^{\prime}$-dimethoxyretrochalcone.

BDZs but also from the pentobarbital, 3 3,21 -dihydroxy- $5 \alpha$ pregnan-20-one (THDOC) and loreclezole modulatory sites. Both the strong dependence of their effects on $\gamma$-subunit and GABA concentration together with their sensitivity to extrasynaptic $\mathrm{GABA}_{\mathrm{A}}$ receptors reveal an original action mode for these trans-retrochalcones. Our results are therefore helpful in understanding the molecular mechanism underlying the modulation by the trans-retrochalcones of brain $\mathrm{GABA}_{\mathrm{A}}$ receptors.

\section{Methods}

\section{Chemicals}

Rc-OMe, trans-6-bromo-4'-methoxyretrochalcone (Rc-Br) and 4,3'-dimethoxychalcone (Ch-OMe) were synthesized as 
described next. Other drugs were purchased from Sigma (St Louis, MO, USA). All the products were stored in aliquots at $-20^{\circ} \mathrm{C}$. Final concentration of dimethyl sulphoxide, if present, never exceeded $0.3 \%$ throughout experiments performed in this study, and this concentration had no effect on GABA-elicited currents.

\section{Synthesis of Rc-OMe, Rc-Br and Ch-OMe}

An aqueous solution of sodium hydroxide $(60 \%, 25 \mathrm{~mL})$ was added to a solution of 2-hydroxy-4-methoxy-benzaldehyde (5 mM; for Rc-OMe), 3-methoxy-benzaldehyde $(5 \mathrm{mM}$; for Ch-OMe), or 2-hydroxy-4-bromo-benzaldehyde ( $5 \mathrm{mM}$; for $\mathrm{Rc}-\mathrm{Br})$ and 4-methoxyacetophenone in methanol $(25 \mathrm{~mL})$. The reaction mixture was stirred for $4 \mathrm{~h}$ using a mechanical stirrer. The mixture was then poured into ice-cold hydrochloric acid ( $\mathrm{pH}$ adjusted to 2). The solid obtained was filtered, dissolved in dichloromethane $(150 \mathrm{~mL})$ and washed with a saturated aqueous solution of sodium bicarbonate. The organic layer was then collected, dried, and evaporated to dryness. The residue obtained was crystallized from methanol. Yield was 60-70\%.

Rc-OMe: $\mathrm{RMN}{ }^{1} \mathrm{H}\left(300 \mathrm{MHz}, \mathrm{CD}_{3} \mathrm{OD}, 25^{\circ} \mathrm{C}\right): \delta=3.78(\mathrm{~s}$, $3 \mathrm{H}), 3.88(\mathrm{~s}, 3 \mathrm{H}), 6.80\left(\mathrm{~d}, 1 \mathrm{H},{ }^{3} \mathrm{~J}=8.8 \mathrm{~Hz}\right), 6.86\left(\mathrm{dd}, 1 \mathrm{H},{ }^{3} \mathrm{~J}=\right.$ $\left.8.8 \mathrm{~Hz},{ }^{4} \mathrm{~J}=2.9 \mathrm{~Hz}\right), 7.04(\mathrm{~m}, 2 \mathrm{H}), 7.20\left(\mathrm{~d}, 1 \mathrm{H},{ }^{4} \mathrm{~J}=2.9 \mathrm{~Hz}\right)$, $7.78\left(\mathrm{~d}, 1 \mathrm{H},{ }^{3} \mathrm{~J}=15.7 \mathrm{~Hz}\right), 8.06(\mathrm{~m}, 2 \mathrm{H}), 8.07\left(\mathrm{~d}, 1 \mathrm{H},{ }^{3} \mathrm{~J}=\right.$ $15.7 \mathrm{~Hz})$ ppm. $\mathrm{RMN}{ }^{13} \mathrm{C}\left(75 \mathrm{MHz}, \mathrm{CD}_{3} \mathrm{OD}, 25^{\circ} \mathrm{C}\right): \delta=54.6$, 54.9, 112.2, 113.6, 116.6, 118.3, 121.1, 122.0, 130.6, 130.9, 140.1, 151.6, 153.0, 163.8, $190.1 \mathrm{ppm}$.

Rc-Br: $\mathrm{RMN}^{1} \mathrm{H}\left(400 \mathrm{MHz}, \mathrm{CD}_{3} \mathrm{OD}, 25^{\circ} \mathrm{C}\right): \delta=3.90(\mathrm{~s}, 3 \mathrm{H})$, $6.84\left(\mathrm{~d}, 1 \mathrm{H},{ }^{3} \mathrm{~J}=8.8 \mathrm{~Hz}\right), 7.06\left(\mathrm{~d}, 2 \mathrm{H},{ }^{3} \mathrm{~J}=9.2 \mathrm{~Hz}\right), 7.35(\mathrm{dd}, 1 \mathrm{H}$, $\left.{ }^{3} \mathrm{~J}=8.8 \mathrm{~Hz},{ }^{4} \mathrm{~J}=2.4 \mathrm{~Hz}\right), 7.82\left(\mathrm{~d}, 1 \mathrm{H},{ }^{4} \mathrm{~J}=2.4 \mathrm{~Hz}\right), 7.83(\mathrm{~d}, 1 \mathrm{H}$, $\left.{ }^{3} \mathrm{~J}=16.0 \mathrm{~Hz}\right), 7.99\left(\mathrm{~d}, 1 \mathrm{H},{ }^{3} \mathrm{~J}=15.6 \mathrm{~Hz}\right), 8.09\left(\mathrm{~d}, 2 \mathrm{H},{ }^{3} \mathrm{~J}=\right.$ $8.8 \mathrm{~Hz})$ ppm. RMN ${ }^{13} \mathrm{C}\left(100 \mathrm{MHz}, \mathrm{CD}_{3} \mathrm{OD}, 25^{\circ} \mathrm{C}\right): \delta=54.1$, $112.6,115.1,119.0,123.7,125.5,126.6,132.1,132.4,135.2$, 139.8, 157.9, 165.4, $191.2 \mathrm{ppm}$.

Ch-OMe: RMN ${ }^{1} \mathrm{H}\left(400 \mathrm{MHz}, \mathrm{CDCl}_{3}, 25^{\circ} \mathrm{C}\right): \delta=3.88(\mathrm{~s}$, $3 \mathrm{H}), 3.91(\mathrm{~s}, 3 \mathrm{H}), 6.97(\mathrm{~m}, 1 \mathrm{H}), 7.00\left(\mathrm{~d}, 2 \mathrm{H},{ }^{3} \mathrm{~J}=8.8 \mathrm{~Hz}\right), 7.18$ $(\mathrm{m}, 1 \mathrm{H}), 7.27(\mathrm{~m}, 1 \mathrm{H}), 7.35(\mathrm{~m}, 1 \mathrm{H}), 7.54\left(\mathrm{~d}, 1 \mathrm{H},{ }^{3} \mathrm{~J}=16.0 \mathrm{~Hz}\right)$, $7.78\left(\mathrm{~d}, 1 \mathrm{H},{ }^{3} \mathrm{~J}=15.6 \mathrm{~Hz}\right), 8.06\left(\mathrm{~d}, 1 \mathrm{H},{ }^{3} \mathrm{~J}=8.8 \mathrm{~Hz}\right) \mathrm{ppm}$. RMN ${ }^{13} \mathrm{C}\left(100 \mathrm{MHz}, \mathrm{CDCl}_{3}, 25^{\circ} \mathrm{C}\right): \delta=55.5,55.5,113.4,113.9$, 116.1, 121.0, 122.2, 129.9, 130.8, 131.1, 136.5, 143.9, 160.0, $163.5,188.7 \mathrm{ppm}$.

\section{Mutagenesis}

pSN3 plasmids containing the cDNA encoding all the human $\mathrm{GABA}_{\mathrm{A}}$ subunits used in this study were generously provided by Marianne L. Jensen, Neurosearch, Denmark. Site-directed mutagenesis was carried out using the QuickChange ${ }^{\circledR}$ II Sitedirected mutagenesis kit (Stratagene, La Jolla, CA, USA) and mutation was confirmed by DNA sequencing.

\section{Cell culture and transfection in \\ HEK-293 cells}

HEK-293 cells were cultured in Dulbecco's modified Eagle's medium supplemented with 10\% fetal bovine serum (Invitrogen, Carlsbad, CA, USA), 1X GlutaMax, $100 \mathrm{U} \cdot \mathrm{mL}^{-1}$ penicillin and $100 \mu \mathrm{g} \cdot \mathrm{mL}^{-1}$ streptomycin (Invitrogen). Trypsin-treated cells were seeded onto glass coverslips in $35 \mathrm{~mm}$ dishes pretreated with poly-L-Lysine (Sigma) 1 day before transfection and incubated at $37^{\circ} \mathrm{C}$ with $5 \% \mathrm{CO}_{2}$. To ensure the incorporation of the $\gamma$ (or $\delta$ ) subunit to the receptor, HEK-293 cells were transfected with $0.3 \mu \mathrm{g}$ cDNAs in a 1:1:10 ratio of $\alpha: \beta: \gamma$ (or $\delta$ ) (Boileau et al., 2002) using calcium phosphate precipitation. A green fluorescent protein cDNA construct $(0.3 \mu \mathrm{g})$ was added to identify cells that were effectively transfected. Cells were washed 1 day after transfection with fresh medium and used within 24-72 h.

\section{Preparations of hippocampal CA1 pyramidal neurones and thatamic neurones}

For hippocampal CA1 pyramidal neurones, Wistar rats, at postnatal day (P) 12-18, were decapitated under pentobarbital sodium anaesthesia $\left(100 \mathrm{mg} \cdot \mathrm{kg}^{-1}\right.$, i.p.). For thalamic neurones, 3-5 week-old Wistar rats were used. Coronal brain slices containing hippocampus or ventrobasal thalamus at a thickness of $400 \mu \mathrm{m}$ were prepared by use of a microslicer (VT-1000S; Leica, Nussloch, Germany). Slices were kept in a control incubation solution (see next) saturated with $95 \% \mathrm{O}_{2}$ and $5 \% \mathrm{CO}_{2}$ at room temperature $\left(22-24^{\circ} \mathrm{C}\right)$ for at least $1 \mathrm{~h}$ before mechanical dissociation. Slices were then transferred into a $35 \mathrm{~mm}$ culture dish (Primaria 3801; Becton Dickinson, Rutherford, NJ, USA) containing the standard external solution (see next), and the hippocampal CA1 or ventrobasal thalamus regions were identified under a binocular microscope. Details of the mechanical dissociation procedure used to isolate single neurones with adherent and functional presynaptic boutons have been given previously (Rhee et al., 1999; Akaike and Moorhouse, 2003). Briefly, a fire-polished glass micropipette was placed on the surface of the brain slice, and the tip of the pipette was vibrated horizontally at 30-60 Hz for about 2 min using a piezoelectric manipulator (CELL ISOLATOR, K.T. Lab, Saitama, Japan). Slices were removed and the mechanically dissociated neurones allowed to settle and adhere to the bottom of the dish for at least 10 min before recordings commenced.

\section{Electrophysiology of HEK-293 cells}

Currents were recorded using the whole-cell configuration of the patch-clamp technique only from fluorescent cells. Cells were maintained at a holding potential of $-60 \mathrm{mV}$ except for the voltage-dependence experiments. Patch pipettes (3-5 M $\Omega$ ) contained (mM): $140 \mathrm{KCl}, 5 \mathrm{MgCl}_{2}, 5$ EGTA, 10 HEPES, pH 7.3. External solution contained (mM): $140 \mathrm{NaCl}, 2.8 \mathrm{KCl}, 2 \mathrm{CaCl}_{2}$, $2 \mathrm{MgCl}_{2}, 10$ glucose, 10 HEPES, pH 7.3. In these conditions, the theoretical Nernst equilibrium potential of $\mathrm{Cl}^{-}$current is $-0.1 \mathrm{mV}$. The solutions were delivered through three parallel tubes placed immediately above the cell. These tubes were horizontally displaced with the aid of a computer-driven system (SF 77A Perfusion fast step, Warner, Hamden, CT, USA) that ensures solution exchange in 5-10 ms. GABA and/or GABA plus modulators were applied briefly (2-3 s) with a washout period of at least $30 \mathrm{~s}$ between applications.

\section{Electrophysiology of hippocampal CA1 pyramidal neurones and thalamic neurones}

All electrical measurements were performed using the conventional whole-cell patch recording with Axopatch 200B amplifier (Molecular Devices, Sunnyvale, CA, USA) at room temperature. The neurones were voltage clamped at a holding potential $\left(\mathrm{V}_{\mathrm{H}}\right)$ of $-65 \mathrm{mV}$. Membrane potentials were cor- 
rected by $-5 \mathrm{mV}$ to compensate for the patch pipette-bath liquid junction potential. Patch pipettes were made by a PC-10 microelectrode puller (Narishige, Tokyo, Japan) from capillary glass with an inner filament (GD-1.5; Narishige). The resistance of the recording pipettes filled with internal solution (see next) was 5-7 M . Isolated neurones were viewed under phase contrast on an inverted microscope (IX71; Olympus, Tokyo, Japan). Current and voltage were continuously monitored on an oscilloscope (VC-6725; Hitachi, Tokyo, Japan). Membrane currents were filtered at $2 \mathrm{kHz}$, digitized at $10 \mathrm{kHz}$ and stored on a personal computer equipped with pClamp 8.2 (Molecular Devices, Sunnyvale, CA, USA). The ionic composition of the control incubation solution consisted of (mM): $124 \mathrm{NaCl}, 5 \mathrm{KCl}, 1.3 \mathrm{KH}_{2} \mathrm{PO}_{4}, 24$ $\mathrm{NaHCO}_{3}, 2.4 \mathrm{CaCl}_{2}, 1.3 \mathrm{MgCl}_{2}$ and 10 glucose saturated with $95 \% \mathrm{O}_{2}$ and $5 \% \mathrm{CO}_{2}$. The standard external solution used for recordings from isolated neurones contained $(\mathrm{mM})$ : 150 $\mathrm{NaCl}, 2.5 \mathrm{KCl}, 1.0 \mathrm{MgCl}_{2}, 2.0 \mathrm{CaCl}_{2}, 10$ glucose, 10 HEPES, and was adjusted to a $\mathrm{pH}$ of 7.4 with Tris-base. The standard external solution routinely contained $10 \mu \mathrm{M}$ 6-cyano-7nitroquinozaline-2, 3-dione disodium, $20 \mu \mathrm{M}$ DL-2-amino-5phosphonovaleric acid to block ionotropic glutamatergic currents. Tetrodotoxin $(0.3 \mu \mathrm{M})$ was also added to the recording solution to block the burst activity of spontaneous inhibitory post-synaptic currents (IPSCs) (Inada et al., 2010). The internal (patch-pipette) solution for the whole-cell patch recording contained $(\mathrm{mM}): 90 \mathrm{CsCl}, 55$ Cs-methanesulphonate, 10 HEPES, 2 EGTA, 4 lidocaine $\mathrm{N}$-ethyl chloride, 4 ATP-Mg, 0.4 GTP-Na, and was adjusted to a $\mathrm{pH}$ of 7.3 with Tris-base. Voltage ramps from a $\mathrm{V}_{\mathrm{H}}$ of $-65 \mathrm{mV}$ to $+15 \mathrm{mV}$ for $0.5 \mathrm{~s}$ were applied before and during the application of GABA. To obtain current-voltage relationships, the ramp current measured before the GABA response was subtracted from the current obtained during the response.

\section{Data analysis}

Amplitudes of currents induced by exogenously applied GABA or GABA plus modulators were measured at the peaks of the responses. The modulatory effect on GABA or $4,5,6,7$ tetrahydroisoxazolo[5,4-c]pyridin-3(2H)-one (THIP) response was defined as potentiation (fold) $=\left(I_{\text {agonist+modulator }} / I_{\text {agonist }}\right)-1$, where $I_{\text {agonist }}$ was the agonist-evoked current and $I_{\text {agonist+modulator }}$ was the current evoked by the co-application of agonist plus modulator. Concentration-response relationships for agonist as well as for agonist plus modulator were constructed, and the Hill equation was fitted (IGOR PRO 5.03) to the data according to:

$$
\frac{I}{I_{\max }}=\frac{1}{1+\left(\frac{E C_{50}}{[D]}\right)^{n H}}
$$

where $I$ and $I_{\max }$ were the peak current to a given concentration of the drug and the maximum current, respectively; $E C_{50}$ was the concentration of the drug giving half maximum response; $[D]$ was the drug concentration; and $n H$ was the Hill coefficient. The potentiations were also fitted to the previously mentioned Hill equation, but in which $I$ and $I_{\max }$ were the potentiation elicited by a given concentration of the drug and the maximum potentiation, respectively; $E C_{50}$ was the concentration of the drug giving half maximum potentia- tion, $[D]$ was the drug concentration; and $n H$ was the Hill coefficient. Spontaneous IPSCs were analysed using MiniAnalysis program (Synaptosoft, Leonia, NJ, USA). Only single IPSC events were visually selected for analysing the amplitude and decay kinetics. Data are expressed as mean \pm SEM. Statistical differences were determined using Student's twotailed $t$-test. For multiple groups, one-way ANOVA with Tukey's multiple comparison post hoc test was used.

\section{Results}

\section{Synthesis of trans-retrochalcones}

The retrochalcones Rc-OMe and Rc-Br were prepared through the base-catalyzed Claisen-Schmidt condensation of p-methoxy acetophenone with substituted $o$-OH benzaldehydes while the chalcone $\mathrm{Ch}$-OMe used $m$-OMe benzaldehyde for the condensation. (Stirrett et al., 2008) (Figure 1B).

\section{The synthesized (retro)chalcones are positive allosteric modulators of $\alpha_{1} \beta_{2} \gamma_{2 s} G A B A_{A}$ receptors}

Recombinant $\alpha_{1} \beta_{2} \gamma_{2 s} G_{A B A}$ receptors were expressed in HEK293 cells and the whole-cell configuration of the patch-clamp technique was used to evaluate the action of the three derivatives. GABA EC $\mathrm{E}_{50}$ value was determined (Table 1). The effect of each of the three compounds $(10 \mu \mathrm{M})$ on the GABA $(1 \mu \mathrm{M})$ evoked currents was determined. As depicted in Figure 1C, all three derivatives potentiated, although differently, GABAevoked currents. The trans-retrochalcones Rc-OMe and Rc-Br exhibited higher efficacy than diazepam $(10 \mu \mathrm{M})$, a classical $\mathrm{BDZ}$ allosteric modulator of $\mathrm{GABA}_{\mathrm{A}}$ receptors (Figure $1 \mathrm{C}$ ). By contrast, Ch-OMe potentiated GABA-evoked currents similarly to diazepam (Figure 1C). Overall, these results indicate that the trans-retrochalcones are strong positive allosteric modulators of the $\alpha_{1} \beta_{2} \gamma_{2 s} G_{A B A_{A}}$ receptor. Because the methoxy-derivative potentiated the GABA response approximately to the same extent as the bromo-derivative, we decided to further study these two molecules either separately or together.

\section{Subunit dependence of potentiations induced by Rc-OMe}

We further characterized the action of Rc-OMe at recombinant $\alpha_{1} \beta_{2} \gamma_{2 s}, \alpha_{2} \beta_{2} \gamma_{2 s}, \alpha_{3} \beta_{2} \gamma_{2 s}$ and $\alpha_{4} \beta_{2} \gamma_{2 s} G_{A B A}$ receptors to establish that the potentiation induced by this compound is dependent on the $\alpha$-subunit; the $\alpha_{1} \beta_{2}$ combination was also included to evaluate the contribution of the $\gamma$-subunit for Rc-OMe-induced potentiation. These receptors were functionally expressed in HEK-293 cells (Table 1) and GABA EC -2 concentration was determined for each subunit combination. The concentration-response relationship was then constructed for Rc-OMe-induced potentiations of an $\mathrm{EC}_{-2}$ GABAelicited current at each subunit combination (Figure 2B). Rc-OMe was used up to $100 \mu \mathrm{M}$ because of its limited solubility in buffers.

Rc-OMe potentiated GABA-elicited currents at $\alpha_{1} \beta_{2} \gamma_{2 s}$, $\alpha_{2} \beta_{2} \gamma_{2 s}$ and $\alpha_{3} \beta_{2} \gamma_{2 s}$ (Figure 2A,B), all in a concentrationdependent manner. $\mathrm{EC}_{50}$ values were $17.7 \pm 3.0(n=11)$ and $7.6 \pm 1.6 \mu \mathrm{M}(n=4)$ for $\alpha_{1} \beta_{2} \gamma_{2 s}$ and $\alpha_{2} \beta_{2} \gamma_{2 s}$, respectively, 
Table 1

Functional parameters for Rc-OMe modulation at recombinant wild-type receptors and mutants

\begin{tabular}{|c|c|c|c|c|c|c|c|c|c|c|}
\hline \multirow[b]{2}{*}{ Receptor } & \multicolumn{3}{|l|}{ GABA } & \multicolumn{2}{|c|}{$\begin{array}{l}\text { GABA } \\
\text { (in the presence } \\
\text { of } 30 \mu \mathrm{M} \text { Rc-OMe) }\end{array}$} & & \multicolumn{2}{|c|}{$\begin{array}{l}\text { Rc-OMe } \\
\text { (in the presence } \\
\text { of } \mathrm{EC}_{\sim 2} \mathrm{GABA} \text { ) }\end{array}$} & \multirow[b]{2}{*}{ Fold maximal potentiation } & \multirow[b]{2}{*}{$n$} \\
\hline & $\mathrm{EC}_{50}, \mu \mathrm{M}$ & $n_{H}$ & $n$ & $\mathrm{EC}_{50}, \mu \mathrm{M}$ & $n_{H}$ & $n$ & $\mathrm{EC}_{50}, \mu \mathrm{M}$ & $n_{H}$ & & \\
\hline$\alpha_{1} \beta_{2} \gamma_{2 s}$ & $23.1 \pm 3.3$ & $1.5 \pm 0.1$ & 5 & $12.1 \pm 4.3^{b}$ & $0.7 \pm 0.1^{\mathrm{b}}$ & 5 & $17.7 \pm 3.0$ & $1.6 \pm 0.1$ & $19.6 \pm 2.2($ at $30 \mu \mathrm{M})$ & 11 \\
\hline$\alpha_{2} \beta_{2} \gamma_{2 s}$ & $62.3 \pm 12.8$ & $1.7 \pm 0.1$ & 5 & N.D. & & & $7.6 \pm 1.6$ & $1.4 \pm 0.2$ & $13.6 \pm 2.3($ at $30 \mu \mathrm{M})$ & 4 \\
\hline$\alpha_{3} \beta_{2} \gamma_{2 s}$ & $115.8 \pm 24.7$ & $1.6 \pm 0.3$ & 5 & N.D. & & & N.D. & & $15.2 \pm 1.2($ at $100 \mu \mathrm{M})$ & 5 \\
\hline$\alpha_{4} \beta_{2} \gamma_{2 s}$ & $13.4 \pm 1.3$ & $1.5 \pm 0.1$ & 6 & $33.4 \pm 15.5$ & $0.9 \pm 0.1^{b}$ & 6 & $8.1 \pm 3.4$ & $3.8 \pm 1.0$ & $6.2 \pm 1.4($ at $30 \mu \mathrm{M})$ & 5 \\
\hline$\alpha_{1} \beta_{2}$ & $3.9 \pm 0.9$ & $1.5 \pm 0.2$ & 4 & N.D. & & & N.D. & & $2.1 \pm 0.3($ at $10 \mu \mathrm{M})$ & 7 \\
\hline$\alpha_{1} \mathrm{H} 101 \mathrm{R} \beta_{2} \gamma_{2 S}$ & $57.0 \pm 11.6^{a}$ & $1.3 \pm 0.1$ & 5 & $185.2 \pm 111.8$ & $0.6 \pm 0.1^{b}$ & 5 & $7.4 \pm 0.9$ & $1.5 \pm 0.2$ & $10.4 \pm 2.0^{\text {a }}$ (at $\left.100 \mu \mathrm{M}\right)$ & 3 \\
\hline$\alpha_{1} \beta_{2} N 265 S \gamma_{2 S}$ & $30.1 \pm 4.9$ & $1.9 \pm 0.2$ & 6 & N.D. & & & N.D. & & $7.8 \pm 0.7^{\mathrm{a}}($ at $30 \mu \mathrm{M})$ & 6 \\
\hline$\alpha_{4} \beta_{3} \delta$ & $3.8 \pm 1.0$ & $1.1 \pm 0.2$ & 6 & N.D. & & & N.D. & & N.D. & \\
\hline$\alpha_{4} \beta_{3}$ & $1.7 \pm 0.4$ & $1.3 \pm 0.2$ & 4 & N.D. & & & N.D. & & N.D. & \\
\hline
\end{tabular}

${ }^{a}$ Values are significantly different from that of $\alpha_{1} \beta_{2} \gamma_{2 s}, P<0.05$ (Student's unpaired t-test).

${ }^{b}$ Values are significantly different from that determined in the absence of Rc-OMe, $P<0.05$ (Student's paired $t$-test).

Rc-OMe, trans-6,4'-dimethoxyretrochalcone; N.D., not determined.

but for $\alpha_{3} \beta_{2} \gamma_{2 s}, \mathrm{EC}_{50}$ could not be determined due to a lack of saturation up to $100 \mu \mathrm{M}$ (Figure $2 \mathrm{~B}$ ). At $\alpha_{1} \beta_{2} \gamma_{2 s}$, because of the bell-shaped curve, the $\mathrm{EC}_{50}$ value might be an underestimate of the true value (Figure $2 \mathrm{~B}$ ). The maximal potentiations reached $19.6 \pm 2.2-, 13.6 \pm 2.3-$ and $15.2 \pm 1.2$-fold at 30,30 and $100 \mu \mathrm{M}$, respectively, at $\alpha_{1} \beta_{2} \gamma_{2 s}, \alpha_{2} \beta_{2} \gamma_{2 s}$ and $\alpha_{3} \beta_{2} \gamma_{2 s}(n=$ 4-11) (Table 1). In the control experiments, diazepam $(3 \mu \mathrm{M})$ potentiated GABA-elicited currents at these receptors $(n=$ 4-11), suggesting the successful incorporation of the $\gamma$-subunit into these expressed receptors (exemplified for $\alpha_{1} \beta_{2} \gamma_{2 s}$ in Figure 2A).

Unexpectedly, Rc-OMe potentiated GABA-elicited currents at $\alpha_{4} \beta_{2} \gamma_{2 s}$ with a $6.2 \pm 1.4$-fold maximal potentiation observed at $30 \mu \mathrm{M}(n=5)$, and the concentrationresponse curve was also a bell-shaped curve (Figure 2 and Table 1). Diazepam $(3 \mu \mathrm{M})$, as expected, did not potentiate GABA-elicited currents at this classical BDZ insensitive receptor $(n=5)$ (Figure $2 \mathrm{~A})$. Taken together, the observed potentiating extent was $\alpha_{1} \beta_{2} \gamma_{2 s}>\alpha_{2} \beta_{2} \gamma_{2 s} \approx$ $\alpha_{3} \beta_{2} \gamma_{2 s}>\alpha_{4} \beta_{2} \gamma_{2 s}$.

Rc-OMe by itself (up to $100 \mu \mathrm{M}$ ) evoked only tiny currents in the cells expressing each of these four combinations $(<8.3 \%$ of the maximal GABA-evoked currents in all cases, data not shown), indicating a very poor $\mathrm{GABA}_{\mathrm{A}}$ receptor agonist action for Rc-OMe.

The maximal potentiation at $\alpha_{1} \beta_{2}$ receptors was only 2.1 \pm 0.3 -fold (at $10 \mu \mathrm{M}, n=7$ ), highly reduced compared with that at $\alpha_{1} \beta_{2} \gamma_{2 s}(19.6 \pm 2.2$-fold, $n=11)$, suggesting that the potentiation induced by Rc-OMe depends strongly on the presence of the $\gamma$-subunit (Figure 2).

Moreover, a rebound current was observed upon washout after co-application of GABA and Rc-OMe $(100 \mu \mathrm{M})$ (Figure 2), indicating that at high concentration Rc-OMe may act as an open channel blocker at $\alpha_{1} \beta_{2}$. Diazepam $(3 \mu \mathrm{M})$, as expected, did not potentiate GABA-elicited currents at this BDZ-insensitive receptor $(n=7)$ (Figure 2A).

\section{Rc-OMe exerts its potentiation effect mainly through a site different from that of the classical BDZs}

We further investigated the challenging hypothesis that Rc-OMe binds to a site independent of that of the classical BDZs by performing the following additional experiments.

Firstly, Ro 15-1788, an antagonist that binds to the BDZ binding site with nanomolar affinity, was used to inhibit Rc-OMe-induced potentiation at $\alpha_{1} \beta_{2} \gamma_{2 s}$. Ro 15-1788 (10 $\left.\mu \mathrm{M}\right)$ only reduced by $34.4 \pm 3.3 \%$ the potentiation induced by $10 \mu \mathrm{M}$ Rc-OMe $(n=7)$ (Figure 3A), whereas in control experiments Ro 15-1788 abolished the potentiation induced by $3 \mu \mathrm{M}$ diazepam (data not shown). We also verified that $10 \mu \mathrm{M}$ Ro $15-1788$ did not by itself potentiate the GABA response (108 $\pm 8 \%$ of control, $n=6)$.

Secondly, if Rc-OMe and diazepam act through two, topologically different, binding sites, then one can expect an additive effect of the two drugs. Indeed, co-stimulation of the GABA-elicited current with $1 \mu \mathrm{M}$ Rc-OMe plus $3 \mu \mathrm{M}$ diazepam, a concentration that saturates the high-affinity BZD binding site, resulted in a $2.3 \pm 0.7$-fold potentiation, close to the sum of the potentiations recorded on the same cell by $1 \mu \mathrm{M}$ Rc-OMe $(1.1 \pm 0.3$-fold $)$ and $3 \mu \mathrm{M}$ diazepam $(1.7 \pm$ 0.4 -fold) applied separately $(n=5)$ (Figure 3B). This nearadditive effect further strongly supports the notion that the main action site of Rc-OMe is different from that of diazepam.

Finally, we introduced H101R mutation in the $\alpha_{1}$ subunit, a mutation known to abolish the high-affinity binding of classical BDZs (Wieland et al., 1992; Rudolph et al., 1999). Mutant $\alpha_{1} \mathrm{H} 101 \mathrm{R} \beta_{2} \gamma_{2 s}$ was functionally expressed in HEK-293 cells (Table 1) and, as expected, was not responsive to $3 \mu \mathrm{M}$ diazepam (data not shown). By contrast, Rc-OMe still potentiated $\mathrm{EC}_{-2}$ GABA-elicted currents $\left(\mathrm{EC}_{50}=7.4 \pm 0.9 \mu \mathrm{M}\right.$ and 
A
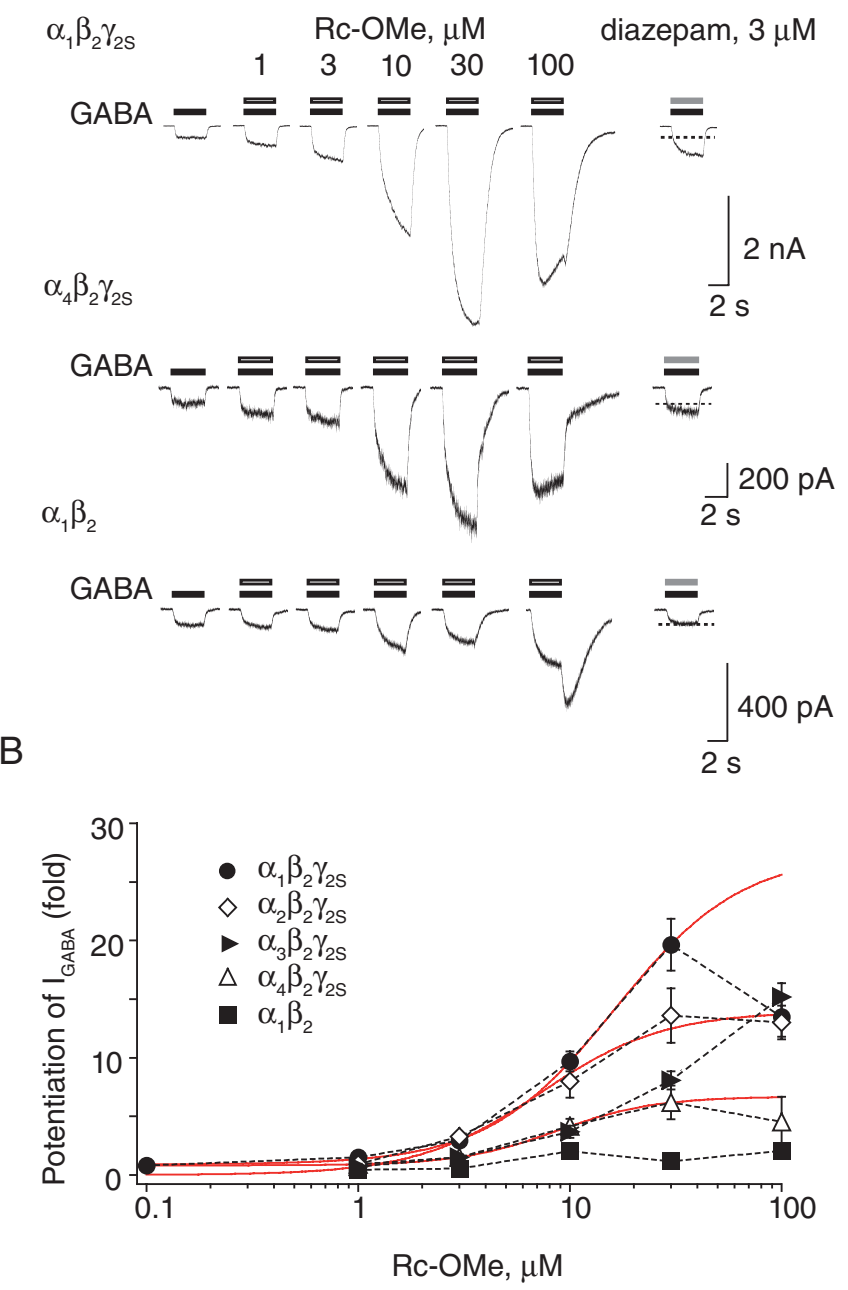

Figure 2

Rc-OMe-induced potentiations of GABA-elicited currents at recombinant $\alpha_{1} \beta_{2} \gamma_{2 s}, \quad \alpha_{2} \beta_{2} \gamma_{2 s}, \alpha_{3} \beta_{2} \gamma_{2 s}, \quad \alpha_{4} \beta_{2} \gamma_{2 s}$ and $\alpha_{1} \beta_{2}$ receptors. (A) Examples of current traces showing the effects induced by different concentrations of Rc-OMe on EC ${ }_{2}$ GABA-elicited currents at $\alpha_{1} \beta_{2} \gamma_{22}$, $\alpha_{4} \beta_{2} \gamma_{2 s}$ and $\alpha_{1} \beta_{2}$. Also shown are the control experiments carried out in the same cells with diazepam $(3 \mu \mathrm{M})$. (B) Concentration-response curves for Rc-OMe-induced potentiations of EC $\mathrm{C}_{2}$ GABA currents at $\alpha_{1} \beta_{2} \gamma_{2 s}, \alpha_{2} \beta_{2} \gamma_{2 s}, \alpha_{3} \beta_{2} \gamma_{2 s}, \alpha_{4} \beta_{2} \gamma_{2 s}$ and $\alpha_{1} \beta_{2}$ receptors (EC -2 concentrations are $1,4,6,1$ and $0.15 \mu \mathrm{M}$ respectively). Data (data points at $100 \mu \mathrm{M}$ for $\alpha_{1} \beta_{2} \gamma_{2 s}$ and $\alpha_{4} \beta_{2} \gamma_{2 s}$ are not included) are fitted to the Hill equation (in red) except for $\alpha_{1} \beta_{2}$ and $\alpha_{3} \beta_{2} \gamma_{2 s}$ receptors. Data points and error bars in this figure and all other figures represent mean \pm SEM. Rc-OMe, trans-6,4'-dimethoxyretrochalcone.

maximal potentiation $=10.4 \pm 2.0$-fold at $100 \mu \mathrm{M}, n=3$ ) in these mutants, although less efficiently than at wild-type (wt) receptors (Figure 3C). Interestingly, a high concentration of Rc-OMe $(100 \mu \mathrm{M})$ did not induce an inhibitory effect with this mutant, an effect previously observed with the wt receptor. These results suggest that the absence of the high-affinity BDZ binding site has moderate impact on the potentiations induced by Rc-OMe.
A
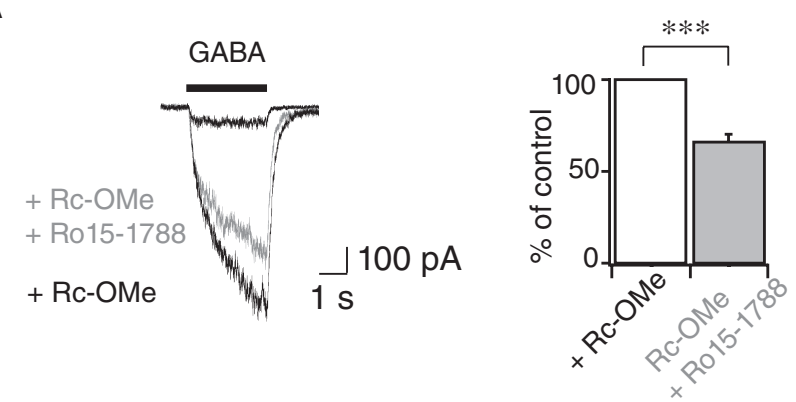

B
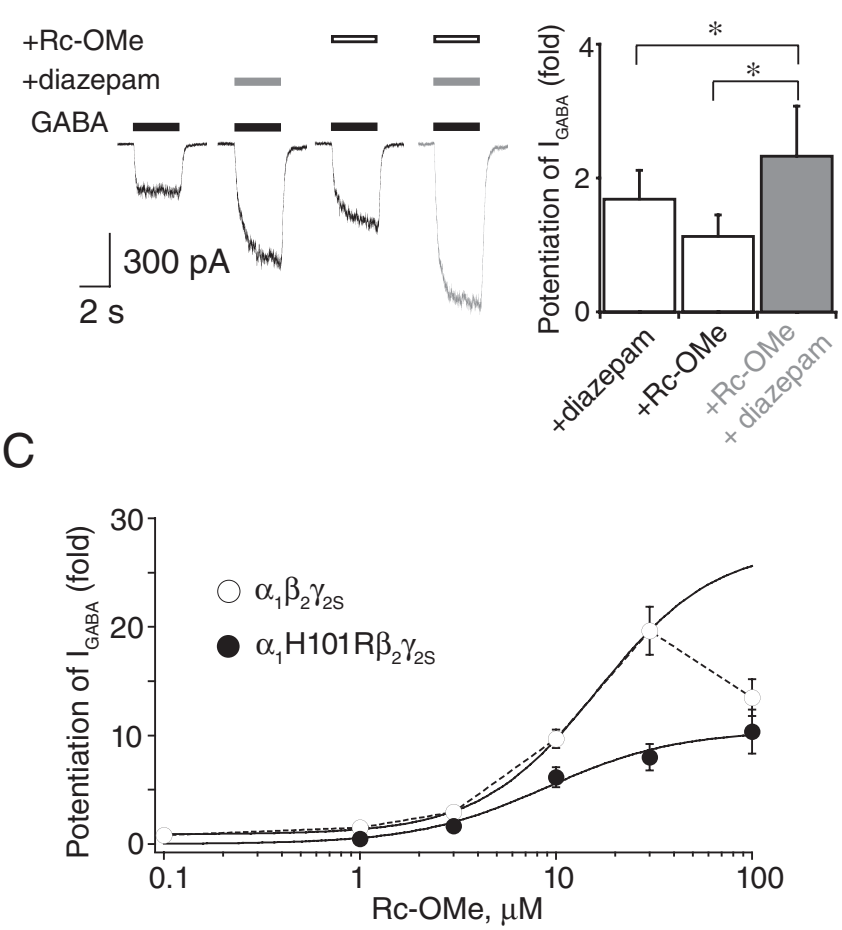

Figure 3

Rc-OMe-induced potentiation is mediated through a site independent of that of the classical BDZs. (A) Left, examples of current traces showing the potentiation induced by Rc-OMe $(10 \mu \mathrm{M})$ (black trace) or by Rc-OMe $(10 \mu \mathrm{M})$ plus Ro $15-1788(10 \mu \mathrm{M})$ (grey trace); the GABA-elicited current $(1 \mu \mathrm{M})$ is also shown. Right, summary of inhibition induced by the presence of Ro 15-1788 $(n=7)$, control was set to $100 \%$. ${ }^{* *} P<0.0001$ (Student's paired $t$-test). (B) Left, examples of current traces showing potentiations of GABA-evoked currents $(1 \mu \mathrm{M})$ induced by Rc-OMe $(1 \mu \mathrm{M})$ or diazepam $(3 \mu \mathrm{M})$, or by diazepam $(3 \mu \mathrm{M})$ plus Rc-OMe $(1 \mu \mathrm{M})$. Right, summary of additive potentiation induced by Rc-OMe plus diazepam $(n=5)$. ${ }^{*} P<$ 0.05 (Student's paired $t$-test). (C) Concentration-response curve for Rc-OMe-induced potentiations of $\mathrm{EC}_{-2}$ GABA currents $(3 \mu \mathrm{M})$ at $\alpha_{1} \mathrm{H} 101 \mathrm{R} \beta_{2} \gamma_{2 s}(n=3)$. Data were fitted to the Hill equation. Data and fitted curve for wt receptor were taken from Figure 2B. $\mathrm{BDZ}$, benzodiazepine; Rc-OMe, trans-6,4'-dimethoxyretrochalcone; wt, wild type.

Taken together, these three sets of experiments clearly demonstrate that Rc-OMe exerts its potentiation effect mainly through a site different from that of the classical BDZ binding site. 

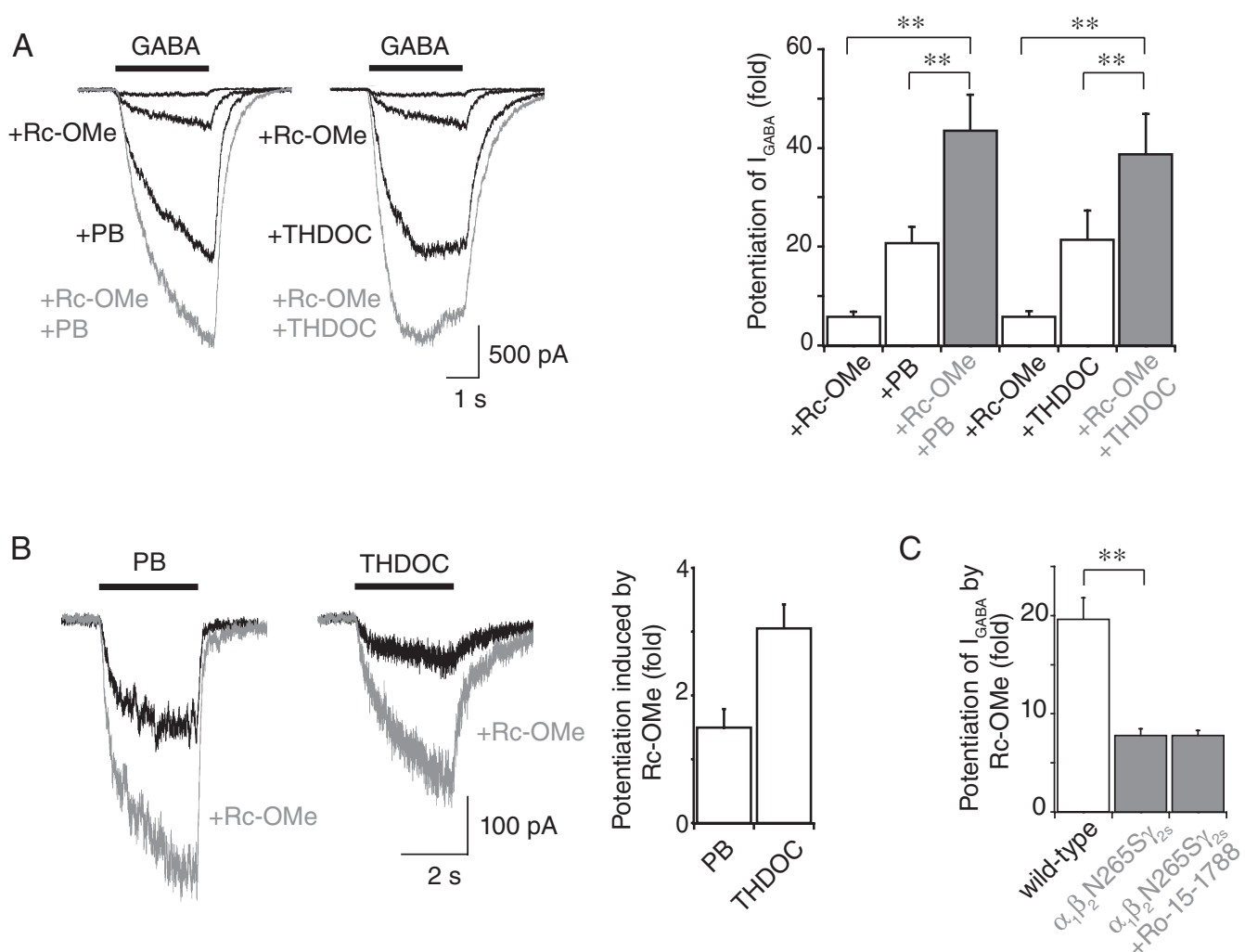

\section{Figure 4}

Rc-OMe-induced potentiation is mediated through a site independent of those of pentobarbital (PB), 3 $\alpha, 21$-dihydroxy-5 $\alpha$-pregnan-20-one (THDOC) and loreclezole. (A) Left, examples of current traces showing the supra-additive potentiation of GABA-evoked currents ( $1 \mu \mathrm{M})$ by Rc-OMe $(10 \mu \mathrm{M})$ plus PB $(100 \mu \mathrm{M})$ or by Rc-OMe $(10 \mu \mathrm{M})$ plus THDOC $(3 \mu \mathrm{M})$ at $\alpha_{1} \beta_{2} \gamma_{22}$. Right, summary of supra-additive potentiation induced by Rc-OMe plus PB $(n=8)$ or by Rc-OMe plus THDOC $(n=7) .{ }^{* *} P<0.01$ (Student's paired $t$-test). (B) Left, examples of traces of the potentiation of PB $(100 \mu \mathrm{M})$-evoked current or of THDOC $(3 \mu \mathrm{M})$-evoked current induced by Rc-OMe $(10 \mu \mathrm{M})$. Right, summary of potentiations of PB-evoked currents $(n=5)$ or of THDOC ( $3 \mu \mathrm{M})$-evoked currents $(n=5)$ induced by Rc-OMe at $\alpha_{1} \beta_{2} \gamma_{2 s}$. (C) Summary of the potentiation of EC ${ }_{-2}$ GABA-elicited currents $(1.5 \mu \mathrm{M})$ induced by Rc-OMe $(30 \mu \mathrm{M})$ at the mutant $\alpha_{1} \beta_{2} \mathrm{~N} 265 S \gamma_{25}$ in the absence and presence of Ro $15-1788(10 \mu \mathrm{M})(n=4-6)$ as compared with that obtained at wt (data for wt are taken from Figure $2 \mathrm{~B}, n=13$ ). ${ }^{\star *} P<0.01$ (Student's unpaired $t$-test). Rc-OMe, trans-6,4'dimethoxyretrochalcone; wt, wild type.

\section{Rc-OMe does not mediate its action through pentobarbital- and neurosteroid-binding sites} To gain further insights into the molecular mechanism underlying potentiations induced by Rc-OMe, we adopted the concept of additivity to distinguish the action site of Rc-OMe from those of pentobarbital (PB) and THDOC, which are classified as a general anaesthetic and neurosteroid, respectively, both acting as positive modulators of $\mathrm{GABA}_{\mathrm{A}}$ receptors.

At $\alpha_{1} \beta_{2} \gamma_{2 s}$, co-stimulation of GABA-elicited currents by Rc-OMe $(10 \mu \mathrm{M})$ and PB $(100 \mu \mathrm{M})$ resulted in a supra-additive effect of a $43.5 \pm 7.3$-fold potentiation, while in the same cell Rc-OMe and PB exerted a $5.8 \pm 1.0$-fold and a $20.8 \pm 3.4$-fold potentiation $(n=8)$ respectively (Figure $4 \mathrm{~A})$.

This supra-additive effect was also observed with Rc-OMe $(10 \mu \mathrm{M})$ and THDOC $(3 \mu \mathrm{M})$, leading to a $38.7 \pm$ 8.2-fold potentation while Rc-OMe and THDOC exerted a $5.8 \pm 1.0$-fold and a $21.4 \pm 5.9$-fold potentiation $(n=7)$ respectively (Figure 4A). PB $100 \mu \mathrm{M}$ and $3 \mu \mathrm{M}$ THDOC were chosen because these concentrations induce their maximal potentiation effect at $\alpha_{1} \beta_{2} \gamma_{2 s}$ (Thompson et al., 1996; Hosie et al., 2006). These supra-additive rather than competitive effects strongly suggest that the site of action of Rc-OMe for mediating its potentiation effects at $\mathrm{GABA}_{\mathrm{A}}$ receptors is different from those of $\mathrm{PB}$ and THDOC.

In HEK-293 cells expressing $\alpha_{1} \beta_{2} \gamma_{2 s}$, either $100 \mu \mathrm{M}$ PB or $3 \mu \mathrm{M}$ THDOC by itself evoked $\mathrm{Cl}^{-}$currents (Figure $4 \mathrm{~B}$ ), confirming their agonist actions at these concentrations (Thompson et al., 1996; Hosie et al., 2006), and these currents were also potentiated by $10 \mu \mathrm{M}$ Rc-OMe $(1.5 \pm 0.3$-fold and $3.1 \pm$ 0.4 -fold, respectively, for PB and THDOC, $n=5$ ) (Figure 4B). We thus suggest that these currents elicited by PB or THDOC, which were potentiated by Rc-OMe, together with GABAelicited currents, which were potentiated by Rc-OMe plus $\mathrm{PB}$ or THDOC (see Figure 4A), contribute to the previously mentioned supra-additive currents.

Potentiation by Rc-OMe is largely reduced but still present at the mutant $\alpha_{1} \beta_{2} N 265 S \gamma_{2 s}$ The potentiation of GABA-elicited currents induced by loreclezole is abolished in the point mutant $\alpha_{1} \beta_{2} \mathrm{~N} 265 S \gamma_{2 s}$ 
(Wingrove et al., 1994). This mutant was functionally expressed in HEK-293 cells and Rc-OMe $(30 \mu \mathrm{M})$ was applied in the presence of $\mathrm{EC}_{-2}$ GABA concentration (Table 1). The potentiation induced by diazepam $(3 \mu \mathrm{M})$ was not affected (data not shown), whereas a $7.8 \pm 0.7$-fold $(n=6)$ potentiation induced by Rc-OMe remained strong but was reduced by $60.2 \%$ compared with that in the wt receptor (Figure 4C). Surprisingly, this residual potentiation was not affected by the presence of $10 \mu \mathrm{M}$ Ro 15-1788 (7.8 \pm 0.5fold, $n=4$ ) (Figure 4C), contrasting to its 30\% inhibition at the wt receptor.

\section{The modulatory effects of Rc-OMe at} recombinant $G A B A_{A}$ receptors are dependent on GABA concentration

In HEK-293 cells expressing $\alpha_{1} \beta_{2} \gamma_{2 s}$ or $\alpha_{4} \beta_{2} \gamma_{2 s}$ receptors, GABA dose-response curves were constructed in the absence and presence of Rc-OMe respectively. The presence of Rc-OMe $(30 \mu \mathrm{M})$ profoundly modified the GABA doseresponse curve (Figure 5A), mainly by decreasing the Hill coefficient with a slight decrease of the $\mathrm{EC}_{50}$ value (Table 1 ). The decrease of the Hill coefficient was also observed for $\alpha_{4} \beta_{2} \gamma_{2 s}$ receptors (Figure 5B), but the $\mathrm{EC}_{50}$ values were not affected (Table 1). Furthermore, at a high GABA concentration (i.e. $\geq \mathrm{EC}_{50}$ ), Rc-OMe enhanced the apparent desensitization rates of GABA-evoked currents (Figure 5) at both $\alpha_{1} \beta_{2} \gamma_{2 s}$ and $\alpha_{4} \beta_{2} \gamma_{2 s}$ receptors. Overall, these data show that Rc-OMe potentiates GABA-elicited currents only at low GABA concentrations, but enhances the apparent desensitization rates of GABA-evoked currents at high GABA concentrations.

\section{$\mathrm{Rc}-\mathrm{OMe}$ and $\mathrm{Rc}-\mathrm{Br}$ are potent and efficacious modulators of native BDZ-sensitive $G A B A_{A}$ receptors expressed in hippocampal CA1 pyramidal neurones}

We further investigated the modulatory effects induced by the trans-retrochalcones at native $\mathrm{GABA}_{\mathrm{A}}$ receptors in neurones. In acutely isolated hippocampal CA1 pyramidal neurones, GABA $(1 \mu \mathrm{M})$ consistently evoked an inward current. This GABA response is enhanced by diazepam $(0.5 \mu \mathrm{M})$ (data not shown), suggesting the involvement of $\gamma$-subunit- containing $\mathrm{GABA}_{\mathrm{A}}$ receptors. The GABA response was concentration dependent and the $\mathrm{EC}_{50}$ and Hill coefficient were $3.5 \pm$ $0.4 \mu \mathrm{M}$ and $1.9 \pm 0.2$ respectively $(n=6)$ (Figure S1A,D). The current induced by GABA $(1 \mu \mathrm{M})$ was markedly potentiated by Rc-Br $(3 \mu \mathrm{M})(1.6 \pm 0.5$-fold, $n=8)$ (Figure $6 \mathrm{~A})$ and the response to GABA gradually recovered after washout of Rc-Br. In addition, application of $\mathrm{Rc}-\mathrm{Br}$ enhanced the GABAinduced current, but significantly less than the first application (by $60.8 \pm 4.7 \%, n=8$ ) (Figure 6B). Thus, only one application of Rc-Br plus GABA was made at each recorded neurone to construct the concentration-response curve (Figure 6C). Curve fitting to the pooled data, according to the Hill equation, yielded an $\mathrm{EC}_{50}$ value and Hill coefficient of $0.7 \mu \mathrm{M}$ and $2.0(n=5-6)$ respectively. Rc-OMe also enhanced GABA-elicited currents (Figure 6C) with an $\mathrm{EC}_{50}$ value and Hill coefficient of $1.1 \mu \mathrm{M}$ and $2.6(n=4-6)$ respectively.

A
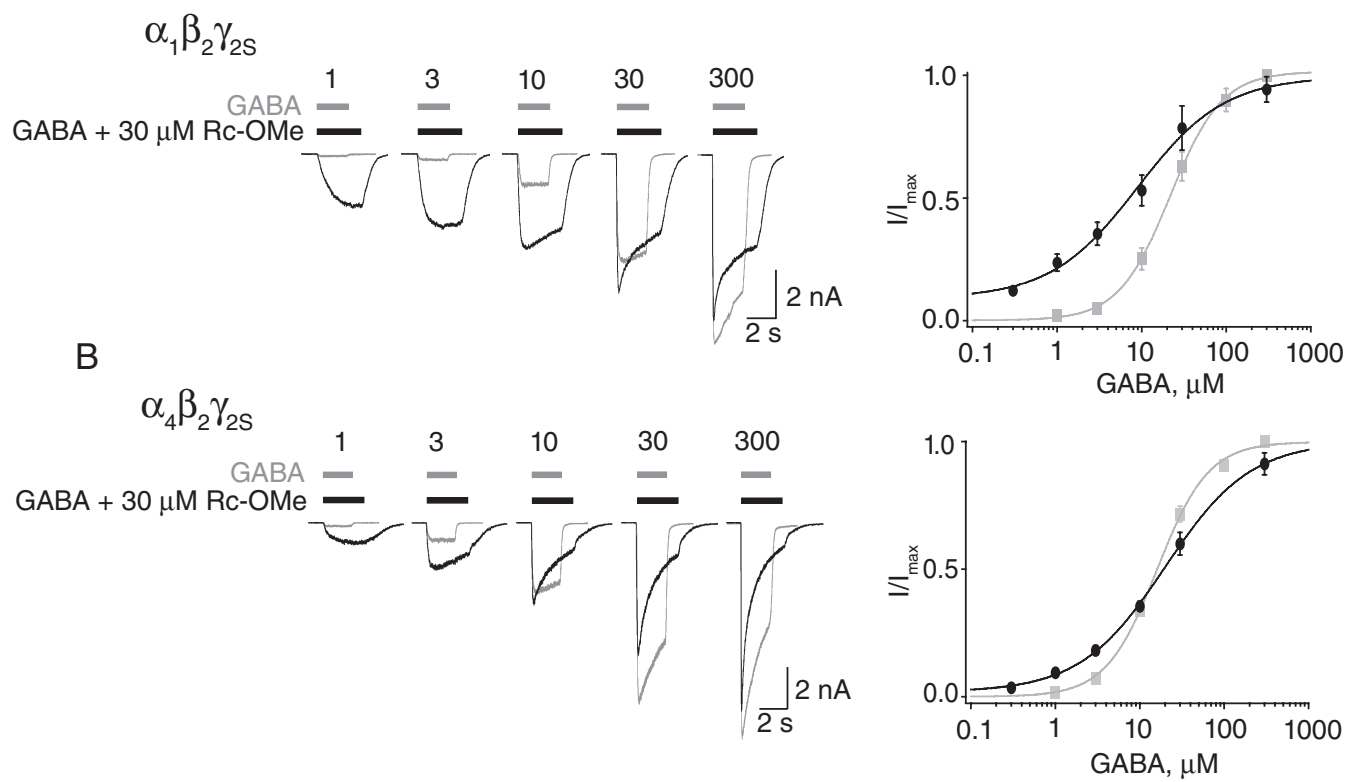

\section{Figure 5}

The effects induced by Rc-OMe at recombinant $\mathrm{GABA}_{A}$ receptors are dependent on GABAconcentration. Left, examples of current traces evoked by different concentrations of GABA in the absence and presence of Rc-OMe at $\alpha_{1} \beta_{2} \gamma_{25}(A)$ and $\alpha_{4} \beta_{2} \gamma_{25}$ (B). Right, GABA concentration-response curves in the absence and presence of Rc-OMe $(30 \mu \mathrm{M})$ at $\alpha_{1} \beta_{2} \gamma_{2 s}(n=5)(\mathrm{A})$ and $\alpha_{4} \beta_{2} \gamma_{2 s}(n=6)$ (B). Data were fitted to the Hill equation. Rc-OMe, trans-6,4'-dimethoxyretrochalcone. 
A

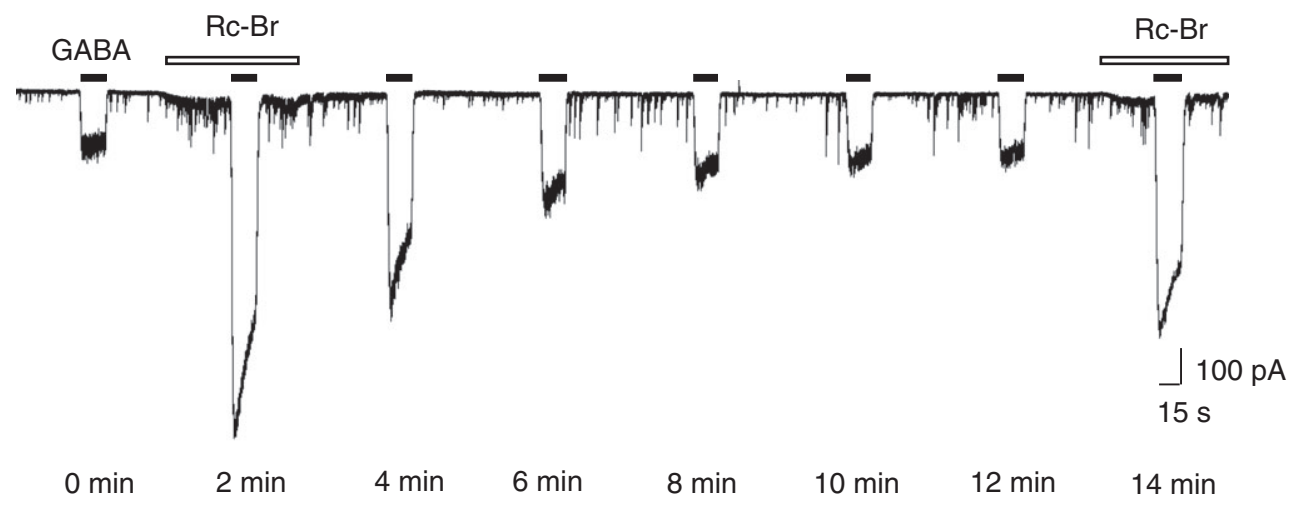

B

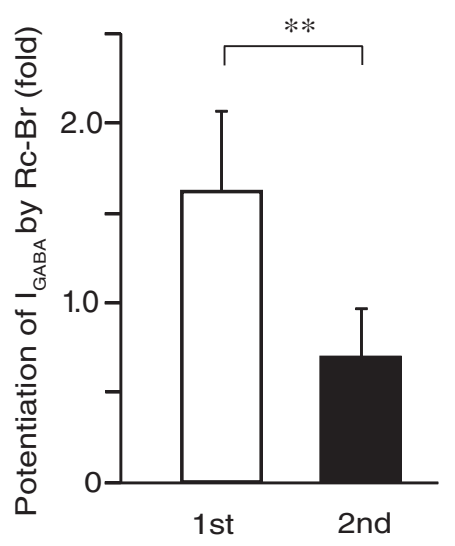

C

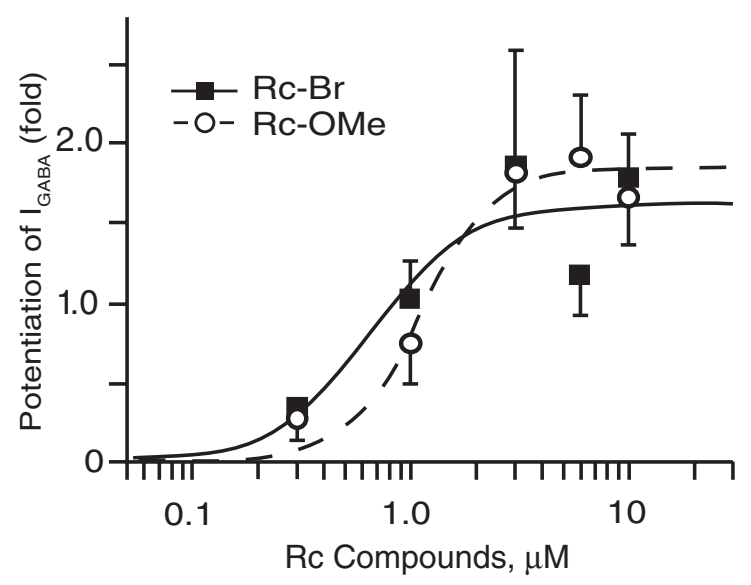

\section{Figure 6}

Effects of $\mathrm{Rc}-\mathrm{Br}$ and $\mathrm{Rc}-\mathrm{OMe}$ on GABA-induced currents in acutely isolated hippocampal CA1 pyramidal neurones. (A) Examples of a current trace showing the effect of $\mathrm{Rc}-\mathrm{Br}$ on the current evoked by GABA. (B) The second application of $\mathrm{Rc}-\mathrm{Br}$ produced a smaller potentiation $(n=8) .{ }^{*} P<0.01$ (Student's paired $t$-test). Current amplitude in the presence of Rc-Br was normalized to that obtained just before $\mathrm{Rc}-\mathrm{Br}$ application. (C) Concentration-response relationships for the potentiation of GABA-elicited current induced by $\mathrm{Rc}-\mathrm{Br}$ and Rc-OMe $(n=4-6)$. Data were fitted to the Hill equation. Rc-Br, trans-6-bromo-4'-methoxyretrochalcone; Rc-OMe, trans-6,4'-dimethoxyretrochalcone.

\section{Potentiation of GABA-elicited currents induced by $\mathrm{Rc}$-OMe or $\mathrm{Rc}-\mathrm{Br}$ is not voltage dependent}

We determined the $I-\mathrm{V}$ curve for the GABA-elicited current $(1 \mu \mathrm{M})$ in the absence and presence of Rc-OMe $(10 \mu \mathrm{M})$ in HEK-293 cells expressing $\alpha_{1} \beta_{2} \gamma_{2 s}$ receptors (Figure S2A). According to the $I-V$ curve, the potentiation of GABA-elicited currents induced by Rc-OMe did not appear to be voltage dependent. The reversal potential was $2.7 \pm 2.9 \mathrm{mV}$ in the absence of Rc-OMe, and $3.8 \pm 3.8 \mathrm{mV}$ in its presence $(n=3)$.

The $I-\mathrm{V}$ curve for the GABA-elicited current $(3 \mu \mathrm{M})$ in the absence and presence of $\mathrm{Rc}-\mathrm{Br}(3 \mu \mathrm{M})$ was determined in hippocampal CA1 pyramidal neurones using a voltage-ramp protocol. Similar to that in the recombinant system with Rc-OMe, no voltage dependence was observed. The reversal potential in the absence and presence of Rc-Br was -11.1 $\pm 1.6 \mathrm{mV}$ and $-15.5 \pm 2.3 \mathrm{mV}(n=7)$ respectively (Figure S2B).

These results suggest that the potentiation of GABAelicited currents induced by the two trans-retrochalcones is not voltage dependent.

\section{$\mathrm{RC}-\mathrm{Br}$ slowed the decay of IPSCS}

Because our dissociated preparations show spontaneous IPSCs (Akaike and Moorhouse, 2003), the effect of Rc-Br on spontaneous IPSCs was also analysed. As shown in Figure 7, Rc-Br $(3 \mu \mathrm{M})$ significantly slowed the decay of IPSCs. The mean half-life $\left(t_{50}\right)$ of IPSC in the absence and presence of Rc-Br was $16.5 \pm 0.9 \mathrm{~ms}$ and $29.8 \pm 1.7 \mathrm{~ms}$ respectively $(n=$ $5)$. On the other hand, Rc-Br had no significant effect on the mean amplitude of the IPSC $(n=5)$. 
A

B
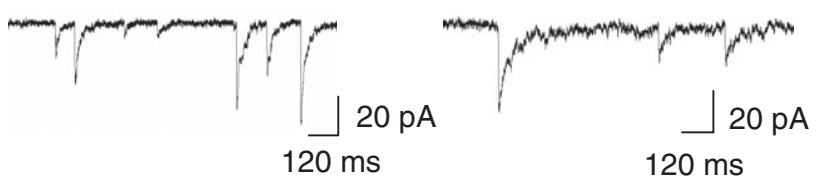

C

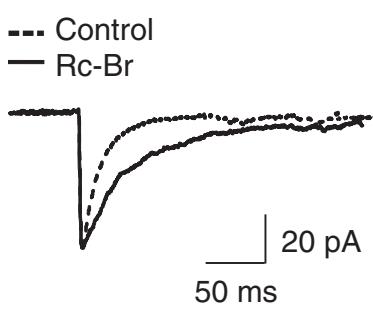

E

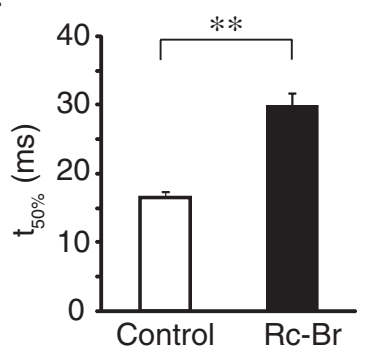

Figure 7

Effect of Rc-Br on spontaneous IPSCs in acutely isolated hippocampal CA1 pyramidal neurones. (A) Examples of current traces showing control IPSCs in the absence of Rc-Br. (B) Spontaneous IPSCs in the presence of $\mathrm{Rc}-\mathrm{Br}(3 \mu \mathrm{M})$. (C) Average IPSC in the absence (dashed line, average from 102 events) and presence (solid line, average from 61 events) of Rc-Br. (D, E) Summary for amplitude (D) and half-time of IPSC (E). ${ }^{* *} P<0.01$ (Student's paired $t$-test). IPSC, inhibitory postsynaptic current; Rc-Br, trans-6-bromo-4'-methoxyretrochalcone.

$\mathrm{Rc}-\mathrm{Br}$ and $\mathrm{Rc}$-OMe are also positive allosteric modulators of extrasynaptic diazepam-insensitive $G A B A_{A}$ receptors expressed in ventrobasal thalamic neurones and of $\alpha_{4} \beta_{3} \delta$ receptors expressed in HEK-293 cells

We finally evaluated the modulatory effects of Rc-Br and Rc-OMe at extrasynaptic diazepam insensitive (possibly $\delta$-subunit containing) $\mathrm{GABA}_{\mathrm{A}}$ receptors expressed in ventrobasal (VB) thalamic neurones. These neurones have synaptic $\left(\alpha_{1} \beta_{2} \gamma_{2}\right)$ and extrasynaptic $\left(\alpha_{4} \beta_{2} \delta\right) G_{A B A}$ receptors (Pirker et al., 2000; Belelli et al., 2005; Peden et al., 2008). The extrasynaptic $\mathrm{GABA}_{\mathrm{A}}$ receptors are pharmacologically and functionally distinct from their synaptic counterparts (Belelli et al., 2009).

The $\mathrm{GABA}_{\mathrm{A}}$ receptors of the isolated neurones were activated by low concentrations $(<1 \mu \mathrm{M})$ of GABA (Figure S1B,D). This high sensitivity is consistent with the properties of the $\alpha_{4} \beta_{2} \delta$ receptors (Jia et al., 2005) but distinct from those observed in reticular thalamic neurones which express no extrasynaptic receptors (Gibbs et al., 1996). A low concentration of THIP $(1 \mu \mathrm{M})$ was used to selectively activate the $\delta$-subunit-containing GABA receptors in the VB neurones (Belelli et al., 2005; Cope et al., 2005; Jia et al., 2005). THIP $(1 \mu \mathrm{M})$ elicited a substantial inward current, which was fully blocked by $2 \mu \mathrm{M}$ SR-95531, a competitive antagonist of the $\mathrm{GABA}_{\mathrm{A}}$ receptor (Figure $8 \mathrm{~A}$ ) but was insensitive to $0.5 \mu \mathrm{M}$ diazepam (Figure $8 \mathrm{C}$ ). Although $\mathrm{GABA}_{\mathrm{A}}$ receptor antagonists have been reported to produce a shift of the holding currents in VB thalamic slice preparations (Cope et al., 2005; Jia et al., 2005), SR-95531 failed to induce detectable changes in the holding currents in our dissociated neurones (Figure 8A). This was because the isolated single neurones had no ambient GABA, which is needed for activation of the extrasynaptic receptors. Markedly, the THIP-elicited current was potentiated by $3 \mu \mathrm{M}$ Rc-Br $(1.9 \pm 0.2$-fold $)$ and $3 \mu \mathrm{M}$ Rc-OMe $(2.1 \pm$ 0.2 -fold) (Figure 8B,C), and these potentiations were not affected by the presence of $20 \mu \mathrm{M}$ Ro $15-1788$ (2.4 \pm 0.3 -fold for Rc-OMe and $3.3 \pm 0.7$-fold for Rc-Br, $n=5-8$ ) (Figure 8C). Decreasing the THIP concentration to $0.1 \mu \mathrm{M}$ still activated inward currents, and Rc-OMe potentiated these currents by $7.1 \pm 1.5$ fold $(n=5$; Figure S3).

To confirm these observations from the VB thalamic neurones, $\alpha_{4} \beta_{3} \delta$ and $\alpha_{4} \beta_{3}$ receptors were expressed in HEK-293 cells (Table 1). Compared with $\alpha_{4} \beta_{3}$ receptors, incorporation of the $\delta$-subunit into functional $\alpha_{4} \beta_{3} \delta$ receptors significantly reduced the extent of the inhibition induced by zinc ( $44 \pm$ $6 \%$ inhibition for $\alpha_{4} \beta_{3}, n=7 ; 12 \pm 6 \%$ for $\alpha_{4} \beta_{3} \delta, n=6$, see Figure 8D,E), in agreement with previous studies (Storustovu and Ebert, 2006), but strongly increased potentiation of $0.3 \mu \mathrm{M}$ GABA-evoked responses (corresponding to $\mathrm{EC}_{-6}$ for $\alpha_{4} \beta_{3} \delta$ and EC -9 for $\left.\alpha_{4} \beta_{3}\right)$ induced by $30 \mu \mathrm{M}$ Rc-OMe (7.5 \pm 2.6-fold for $\alpha_{4} \beta_{3} \delta, n=6 ; 1.1 \pm 0.4$-fold for $\alpha_{4} \beta_{3}, n=6$ ) or $30 \mu \mathrm{M}$ Rc-Br $\left(8.6 \pm 2.6\right.$-fold for $\alpha_{4} \beta_{3} \delta, n=6 ; 1.3 \pm 0.5$-fold for $\alpha_{4} \beta_{3}$, $n=6$, Figure $8 \mathrm{D}, \mathrm{E})$. We finally checked that these GABAevoked responses were virtually insensitive to $3 \mu \mathrm{M}$ diazepam (120 $\pm 4 \%$ of control, $n=4)$. Overall, these data support those obtained in the neurones and strongly suggest that the retrochalcone derivatives are positive allosteric modulators at diazepam-insensitive $\delta$-containing $\mathrm{GABA}_{\mathrm{A}}$ receptors.

\section{Discussion and conclusions}

In this study, two trans-retrochalcones (Rc-OMe and Rc-Br) and a chalcone (Ch-OMe) derivative that were initially shown to act at $\mathrm{GABA}_{\mathrm{A}}$ receptors (Kueny-Stotz et al., 2008) were synthesized and demonstrated to stimulate GABAevoked currents. It should be noted that the two transretrochalcones differ chemically from the chalcone by the presence of the hydroxyl group at position 9 of the aromatic ring A (Figure 1A). The two trans-retrochalcones were found more effective than the chalcone (Ch-OMe) at potentiating GABA-evoked currents at $\alpha_{1} \beta_{2} \gamma_{2 s}$ receptors and consequently were further studied.

The two trans-retrochalcones' modulation of the $\mathrm{GABA}_{\mathrm{A}}$ receptor reveals an original action mode: (i) a novel site of action different from those of BDZs, pentobarbital, THDOC and loreclezole; (ii) strong dependence on the presence of the $\gamma$-subunit; (iii) high dependence on GABA concentration at 


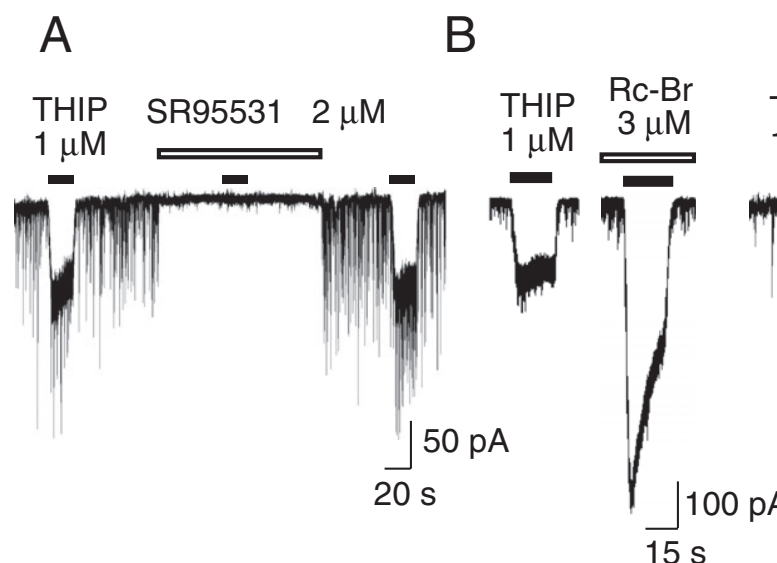

D

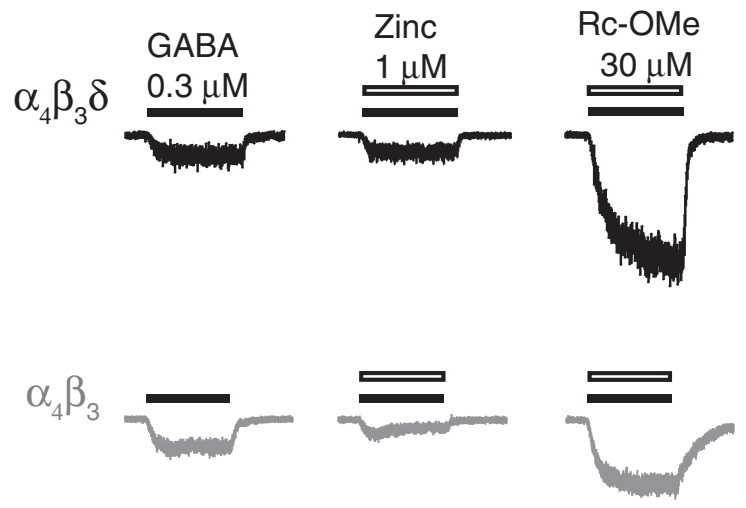

C
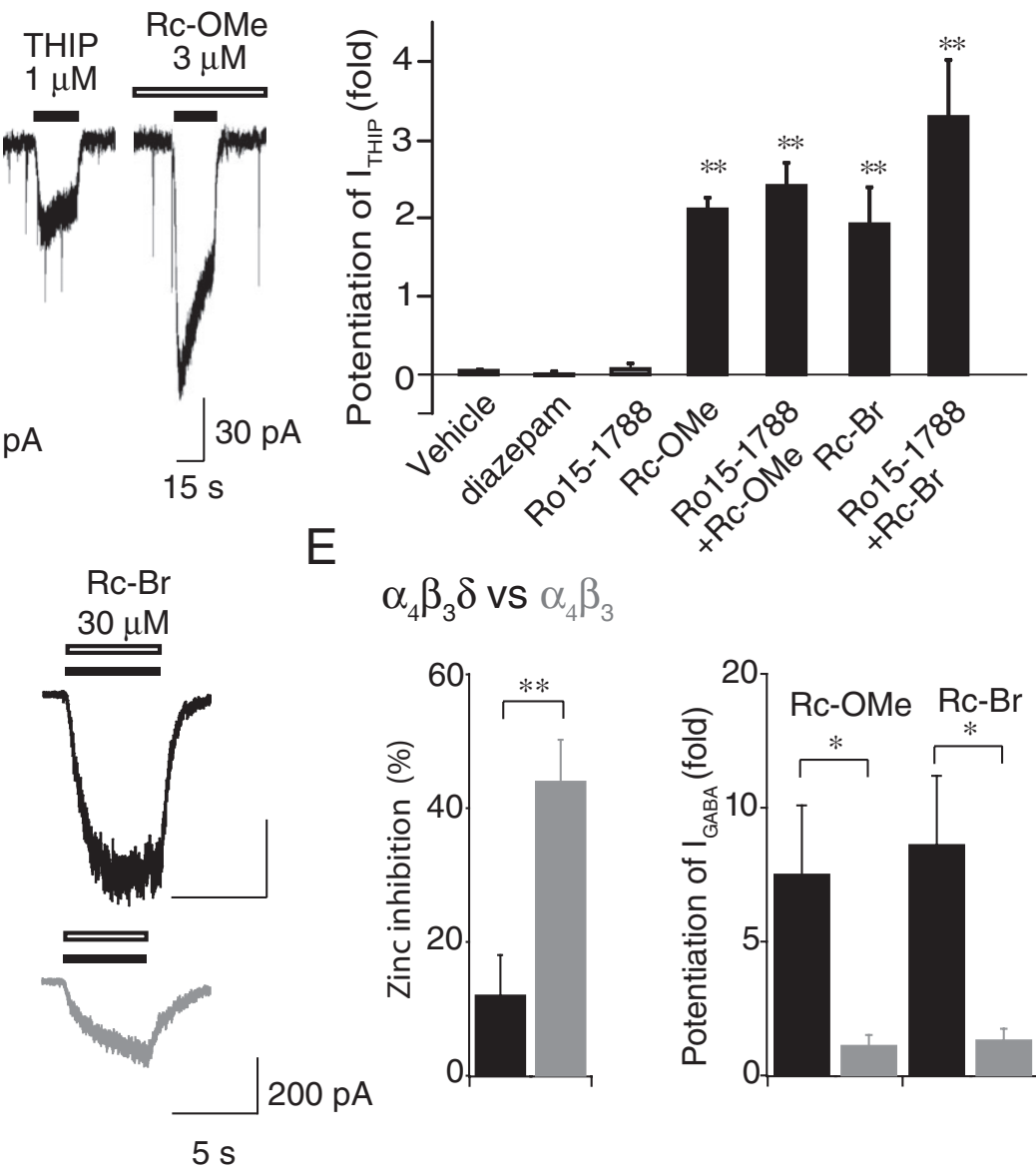

$\alpha_{4} \beta_{3} \delta$ vs $\alpha_{4} \beta_{3}$
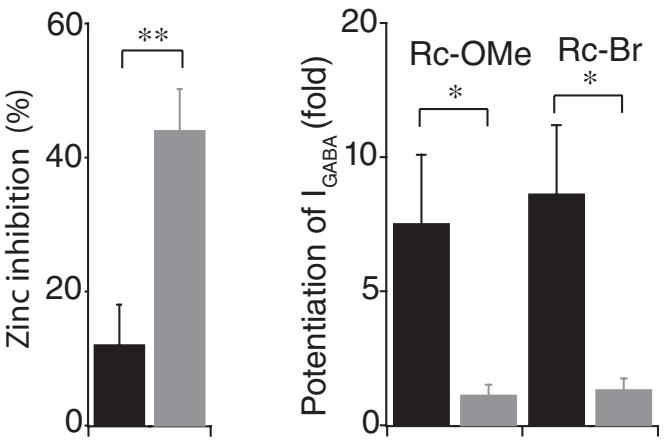

Figure 8

$\mathrm{Rc}-\mathrm{Br}$ and Rc-OMe modulation of $\delta$-containing receptors expressed in ventrobasal (VB) thalamic neurones and in HEK-293 cells. (A) Examples of traces showing the THIP-elicited current that can be blocked by SR95531 $(2 \mu \mathrm{M})$ in VB thalamic neurones. (B) Examples of traces showing the potentiation of THIP-elicited current induced by Rc-Br or by Rc-OMe in VB thalamic neurones. (C) Summary of the experiments shown in (A and B) $(n=5-8) .{ }^{* *} P<0.01$ (compared with vehicle group, ANOVA test). (D) Examples of traces showing the modulation of GABA-elicited current by zinc, Rc-OMe and Rc-Br at $\alpha_{4} \beta_{3}$ and $\alpha_{4} \beta_{3} \delta$ receptors expressed in HEK-293 cells. For each subtype expressed, currents were recorded in the same cell, separated by $\sim 30 \mathrm{~s}$ washout. (E) Summary of the experiments shown in (D). ${ }^{*} P<0.05$, ${ }^{* *} P<0.01$ (Student's unpaired $t$-test). HEK, human embryonic kidney; Rc-Br, trans-6-bromo-4'-methoxyretrochalcone; Rc-OMe, trans-6,4'-dimethoxyretrochalcone; THIP, 4,5,6,7-tetrahydroisoxazolo[5,4-c]pyridin-3(2H)-one.

recombinant synaptic $\mathrm{GABA}_{\mathrm{A}}$ receptors; and (iv) positive modulation of $\delta$-containing $\mathrm{GABA}_{\mathrm{A}}$ receptors. To our knowledge, this is the first time that molecules belonging to the flavonoid family have been shown to act at extrasynaptic $\delta$-containing $\mathrm{GABA}_{\mathrm{A}}$ receptors.

\section{The binding site}

Rc-OMe mainly acts as positive modulator, but at a high concentration $(100 \mu \mathrm{M})$ it also acts as a very poor agonist as well as an open channel blocker. It is thus possible that complex molecular mechanisms could account for Rc-OMe actions and multiple binding sites may exist for mediating the different actions at the $\mathrm{GABA}_{\mathrm{A}}$ receptors. The following part focuses on the site mediating its main action: a strong potentiation effect.

At least 11 distinct binding sites, including agonist recognition sites as well as allosteric sites, have been proposed to exist at the $\mathrm{GABA}_{\mathrm{A}}$ receptors (Johnston, 1996), and cross-talk between these sites has often been reported (Ueno et al., 1997; Williams and Akabas, 2000; Sigel et al., 2001). Supraadditive modulations suggest that the site of action of Rc-OMe is independent to of those of PB and THDOC that mediate both agonist and potentiating actions. Nevertheless, the potentiation induced by Rc-OMe was reduced by $50-60 \%$ in a mutation made either in the classical BDZ binding site located at the extracellular domain or in the loreclezole binding site located in the transmembrane domain. These two sites are topologically distinct, making it unlikely that one retrochalcone molecule binds simultaneously to both sites. A simple explanation for the observed inhibitions is that both the BDZ and loreclezole sites contribute directly, but independently, to Rc-OMe potentiation. However, if this hypothesis was true, the specific BDZ antagonist Ro 17-1588 would have further inhibited the potentiation induced by 
Rc-OMe at $\alpha_{1} \beta_{2} \mathrm{~N} 265 S \gamma_{2 s}$, which was not the case. Another plausible hypothesis is that Rc-OMe binds to a new site, which is somehow allosterically coupled to those of BDZ and loreclezole. This hypothesis is supported by a previous study which showed that binding of diazepam or Ro 17-1588 induces conformational changes at the level of the transmembrane domain (Williams and Akabas, 2000). Nevertheless, it is also possible that the $\mathrm{BDZ}$ and loreclezole binding sites contribute to the Rc-OMe site through a partly overlapping area.

Given that the trans-retrochalcones share a common chemical scaffold with other flavonoids, including flavones and flavans, which have also been demonstrated to modulate $\mathrm{GABA}_{\mathrm{A}}$ receptors at a site independent of the high-affinity classical BDZ binding site (Hall et al., 2004, 2005; Fernandez et al., 2008), it is conceivable that the trans-retrochalcones could share a common binding core with these flavone and flavan derivatives. Nevertheless, it should be noted that the structure-pharmacology relationships are complex for flavonoids acting at the $\mathrm{GABA}_{\mathrm{A}}$ receptors. Although synthetic flavan-3-ol derivatives have also been reported to act as positive modulators at $\mathrm{GABA}_{\mathrm{A}}$ receptors, they displayed little selectivity between $\alpha_{1} \beta_{2}$ and $\alpha_{1} \beta_{2} \gamma_{2 s}$ receptors (Fernandez et al., 2008), whereas Rc-OMe clearly distinguishes $\alpha_{1} \beta_{2} \gamma_{2 s}$ from $\alpha_{1} \beta_{2}$ receptors. In addition, other flavonoids, like chrysin or apigenin, failed to potentiate but rather antagonized $\alpha_{1} \beta_{2} \gamma_{2 s}$ receptors (Goutman et al., 2003). In the present study, our data suggest that a retrochalcone skeleton (due to the presence of the hydroxyl group at position 9 of the aromatic ring A) has more potential than a chalcone skeleton for development as a new modulator of $\mathrm{GABA}_{\mathrm{A}}$ receptors. All these data, including the present study, suggest that within the flavonoids' scaffold different types of $\mathrm{GABA}_{\mathrm{A}}$ modulators can be achieved by subtle chemical modifications.

The finding that Rc-OMe only had a weak potentiating effect at the $\alpha_{1} \beta_{2}$ receptor suggests the $\gamma$-subunit has a major role in its modulating action. The subunit stoichiometry of $\alpha \beta \gamma$ receptors has been established as $2 \alpha: 2 \beta: 1 \gamma$ (Baumann et al., 2002; Boileau et al., 2005), whereas that of $\alpha \beta$ receptors is either $3 \alpha: 2 \beta$ (Boileau et al., 2005) or $2 \alpha: 3 \beta$ (Baumann et al., 2001; Gonzales et al., 2008). Our data suggest that the replacement of an $\alpha$ or a $\beta$-subunit by a $\gamma$-subunit has a dramatic effect on the potentiation induced by Rc-OMe. Thus, to precisely identify the binding site of the transretrochalcones, chimera constructions carrying the $\gamma$-subunit and either the $\alpha$ - or the $\beta$-subunit would be particularly useful. On the other hand, potentiation observed at $\alpha_{4} \beta_{3} \delta$ receptor suggests that the $\gamma$-subunit may not be indispensable for the potentiation by the trans-retrochalcones, raising the possibility that the $\delta$-subunit could also contribute, directly or indirectly, to the trans-retrochalcones' binding site.

\section{The dependence on GABA concentration}

Another pharmacological property of the transretrochalcones is that the potentiation is highly dependent on GABA concentration. The potentiation was very efficacious at $\mathrm{EC}_{-2}$ and null at $\mathrm{EC}_{>50}$. At a high GABA concentration, the apparent desensitization rates of currents were also accelerated in the presence of Rc-OMe. This strong GABA dependence has already been observed for other compounds acting at $\mathrm{GABA}_{\mathrm{A}}$ receptors such as some amphiphiles (Chisari et al.,
$2010)$ as well as a volatile anaesthetic, sevoflurane (Wu et al., 1996). The amphiphiles, including Triton X-100, octyl- $\beta$ glucoside and docosahexaenoic acid, act as potentiators at low GABA concentrations, whereas they act as inhibitors at high concentrations. It has been suggested that the effects of these amphiphiles might be partly non-specific, as they could be due to a decrease in bilayer stiffness and increase in elasticity. It is unlikely that the trans-retrochalcones share a common mechanism with these amphiphiles that underlies the GABA dependence, because the actions of the transretrochalcones are not voltage dependent and the molecules themselves are not charged. More experiments such as single channel analysis and kinetic studies may be useful to address this issue.

The high efficacy of the potentiation induced by the transretrochalcones at very low GABA concentrations may have potential therapeutic implications. One may envisage that when applied to receptors displaying low GABA sensitivity, as observed for some epileptic mutants for which mutations cause channel-gating defects, such compounds will exert their potentiating effects in such a way that they will activate the receptor as efficiently as if the receptor displays a gainof-function phenotype.

Overall, we showed that the trans-retrochalcones are powerful positive allosteric modulators at the synaptic and extrasynaptic $\mathrm{GABA}_{\mathrm{A}}$ receptors with original pharmacological properties. Our data are helpful in understanding the structure-pharmacology relationships for the flavonoid and in developing novel modulators acting on $\mathrm{GABA}_{\mathrm{A}}$ receptors by referring to the retrochalcone scaffold. The fact that the trans-retrochalcones, including their flavylium salts precursors, involve a family displaying a wide range of biological activities reinforced by the novel pharmacological properties shown in this study, indicates we should perform behaviour tests in vivo, in the search for putative therapeutic candidates.

\section{Acknowledgement}

We are grateful to Marianne L. Jensen, Neurosearch, Denmark for generously providing the $\mathrm{GABA}_{\mathrm{A}}$ plasmids.

\section{Conflict of interest}

None.

\section{References}

Akaike N, Moorhouse AJ (2003). Techniques: applications of the nerve-bouton preparation in neuropharmacology. Trends Pharmacol Sci 24: 44-47.

Baumann SW, Baur R, Sigel E (2001). Subunit arrangement of gamma-aminobutyric acid type A receptors. J Biol Chem 276: 36275-36280.

Baumann SW, Baur R, Sigel E (2002). Forced subunit assembly in alpha1beta2gamma2 GABAA receptors. Insight into the absolute arrangement. J Biol Chem 277: 46020-46025. 
Belelli D, Lambert JJ (2005). Neurosteroids: endogenous regulators of the GABA(A) receptor. Nat Rev Neurosci 6: 565-575.

Belelli D, Peden DR, Rosahl TW, Wafford KA, Lambert JJ (2005). Extrasynaptic GABAA receptors of thalamocortical neurons: a molecular target for hypnotics. J Neurosci 25: 11513-11520.

Belelli D, Harrison NL, Maguire J, Macdonald RL, Walker MC, Cope DW (2009). Extrasynaptic GABAA receptors: form, pharmacology, and function. J Neurosci 29: 12757-12763.

Boileau AJ, Baur R, Sharkey LM, Sigel E, Czajkowski C (2002). The relative amount of cRNA coding for gamma2 subunits affects stimulation by benzodiazepines in GABA(A) receptors expressed in Xenopus oocytes. Neuropharmacology 43: 695-700.

Boileau AJ, Pearce RA, Czajkowski C (2005). Tandem subunits effectively constrain GABAA receptor stoichiometry and recapitulate receptor kinetics but are insensitive to GABAA receptor-associated protein. J Neurosci 25: 11219-11230.

Chisari M, Shu HJ, Taylor A, Steinbach JH, Zorumski CF, Mennerick S (2010). Structurally diverse amphiphiles exhibit biphasic modulation of GABAA receptors: similarities and differences with neurosteroid actions. Br J Pharmacol 160: 130-141.

Cope DW, Hughes SW, Crunelli V (2005). GABAA receptor-mediated tonic inhibition in thalamic neurons. J Neurosci 25: 11553-11563.

D'Hulst C, Atack JR, Kooy RF (2009). The complexity of the GABAA receptor shapes unique pharmacological profiles. Drug Discov Today 14: 866-875.

Fernandez SP, Mewett KN, Hanrahan JR, Chebib M, Johnston GA (2008). Flavan-3-ol derivatives are positive modulators of GABA(A) receptors with higher efficacy for the alpha(2) subtype and anxiolytic action in mice. Neuropharmacology 55: 900-907.

Fritschy JM, Benke D, Mertens S, Oertel WH, Bachi T, Mohler H (1992). Five subtypes of type A gamma-aminobutyric acid receptors identified in neurons by double and triple immunofluorescence staining with subunit-specific antibodies. Proc Natl Acad Sci USA 89: 6726-6730.

Gibbs JW, 3rd, Schroder GB, Coulter DA (1996). GABAA receptor function in developing rat thalamic reticular neurons: whole cell recordings of GABA-mediated currents and modulation by clonazepam. J Neurophysiol 76: 2568-2579.

Glykys J, Mody I (2007). Activation of GABAA receptors: views from outside the synaptic cleft. Neuron 56: 763-770.

Gonzales EB, Bell-Horner CL, Dibas MI, Huang RQ, Dillon GH (2008). Stoichiometric analysis of the TM2 6' phenylalanine mutation on desensitization in alpha1beta2 and alpha1beta2gamma2 GABA A receptors. Neurosci Lett 431: 184-189.

Goutman JD, Waxemberg MD, Donate-Oliver F, Pomata PE, Calvo DJ (2003). Flavonoid modulation of ionic currents mediated by GABA(A) and GABA(C) receptors. Eur J Pharmacol 461: 79-87.

Griebel G, Perrault G, Tan S, Schoemaker H, Sanger DJ (1999). Pharmacological studies on synthetic flavonoids: comparison with diazepam. Neuropharmacology 38: 965-977.

Hall BJ, Chebib M, Hanrahan JR, Johnston GA (2004).

Flumazenil-independent positive modulation of gamma-aminobutyric acid action by 6-methylflavone at human recombinant alpha1beta2gamma2L and alpha1beta2 GABAA receptors. Eur J Pharmacol 491: 1-8.
Hall BJ, Chebib M, Hanrahan JR, Johnston GA (2005). 6-Methylflavanone, a more efficacious positive allosteric modulator of gamma-aminobutyric acid (GABA) action at human recombinant alpha2beta2gamma2L than at alpha1beta2gamma2L and alpha1beta2 GABA(A) receptors expressed in Xenopus oocytes. Eur J Pharmacol 512: 97-104.

Hansen RS, Paulsen I, Davies M (2005). Determinants of amentoflavone interaction at the GABA(A) receptor. Eur J Pharmacol 519: 199-207.

Harborne JB, Williams CA (2000). Advances in flavonoid research since 1992. Phytochemistry 55: 481-504.

Heidari MR, Foroumadi A, Amirabadi A, Samzadeh-Kermani A, Azimzadeh BS, Eskandarizadeh A (2009). Evaluation of anti-inflammatory and analgesic activity of a novel rigid 3, 4-dihydroxy chalcone in mice. Ann N Y Acad Sci 1171: 399-406.

Hosie AM, Wilkins ME, Silva HM, Smart TG (2006). Endogenous neurosteroids regulate GABAA receptors through two discrete transmembrane sites. Nature 444: 486-489.

Inada $\mathrm{H}$, Maejima T, Nakahata Y, Yamaguchi J, Nabekura J, Ishibashi H (2010). Endocannabinoids contribute to metabotropic glutamate receptor-mediated inhibition of GABA release onto hippocampal CA3 pyramidal neurons in an isolated neuron/bouton preparation. Neuroscience 165: 1377-1389.

Jia F, Pignataro L, Schofield CM, Yue M, Harrison NL, Goldstein PA (2005). An extrasynaptic GABAA receptor mediates tonic inhibition in thalamic VB neurons. J Neurophysiol 94: 4491-4501.

Jia F, Chandra D, Homanics GE, Harrison NL (2008). Ethanol modulates synaptic and extrasynaptic GABAA receptors in the thalamus. J Pharmacol Exp Ther 326: 475-482.

Johnston GA (1996). GABAA receptor pharmacology. Pharmacol Ther 69: 173-198.

Kueny-Stotz M, Chassaing S, Brouillard R, Nielsen M, Goeldner M (2008). Flavylium salts as in vitro precursors of potent ligands to brain GABA-A receptors. Bioorg Med Chem Lett 18: 4864-4867.

Nielsen M, Frokjaer S, Braestrup C (1988). High affinity of the naturally-occurring biflavonoid, amentoflavon, to brain benzodiazepine receptors in vitro. Biochem Pharmacol 37: 3285-3287.

Olsen RW, Sieghart W (2009). GABA A receptors: subtypes provide diversity of function and pharmacology. Neuropharmacology 56: 141-148.

Peden DR, Petitjean CM, Herd MB, Durakoglugil MS, Rosahl TW, Wafford K et al. (2008). Developmental maturation of synaptic and extrasynaptic GABAA receptors in mouse thalamic ventrobasal neurones. J Physiol 586: 965-987.

Pirker S, Schwarzer C, Wieselthaler A, Sieghart W, Sperk G (2000). GABA(A) receptors: immunocytochemical distribution of 13 subunits in the adult rat brain. Neuroscience 101: 815-850.

Rhee JS, Ishibashi H, Akaike N (1999). Calcium channels in the GABAergic presynaptic nerve terminals projecting to meynert neurons of the rat. J Neurochem 72: 800-807.

Rudolph U, Crestani F, Benke D, Brunig I, Benson JA, Fritschy JM et al. (1999). Benzodiazepine actions mediated by specific gamma-aminobutyric acid(A) receptor subtypes. Nature 401 : 796-800.

Semyanov A, Walker MC, Kullmann DM, Silver RA (2004). Tonically active GABA A receptors: modulating gain and maintaining the tone. Trends Neurosci 27: 262-269. 
Sigel E, Baur R, Furtmueller R, Razet R, Dodd RH, Sieghart W (2001). Differential cross talk of ROD compounds with the benzodiazepine binding site. Mol Pharmacol 59: 1470-1477.

Somogyi P, Fritschy JM, Benke D, Roberts JD, Sieghart W (1996). The gamma 2 subunit of the GABAA receptor is concentrated in synaptic junctions containing the alpha 1 and beta $2 / 3$ subunits in hippocampus, cerebellum and globus pallidus. Neuropharmacology 35: 1425-1444.

Stirrett KL, Ferreras JA, Jayaprakash V, Sinha BN, Ren T, Quadri LE (2008). Small molecules with structural similarities to siderophores as novel antimicrobials against Mycobacterium tuberculosis and Yersinia pestis. Bioorg Med Chem Lett 18: 2662-2668.

Storustovu SI, Ebert B (2006). Pharmacological characterization of agonists at delta-containing GABAA receptors: functional selectivity for extrasynaptic receptors is dependent on the absence of gamma2. J Pharmacol Exp Ther 316: 1351-1359.

Thompson SA, Whiting PJ, Wafford KA (1996). Barbiturate interactions at the human GABAA receptor: dependence on receptor subunit combination. Br J Pharmacol 117: 521-527.

Ueno S, Bracamontes J, Zorumski C, Weiss DS, Steinbach JH (1997). Bicuculline and gabazine are allosteric inhibitors of channel opening of the GABAA receptor. J Neurosci 17: 625-634

Wieland HA, Luddens H, Seeburg PH (1992). A single histidine in GABAA receptors is essential for benzodiazepine agonist binding. J Biol Chem 267: 1426-1429.

Williams DB, Akabas MH (2000). Benzodiazepines induce a conformational change in the region of the gamma-aminobutyric acid type A receptor alpha(1)-subunit M3 membrane-spanning segment. Mol Pharmacol 58: 1129-1136.

Wingrove PB, Wafford KA, Bain C, Whiting PJ (1994). The modulatory action of loreclezole at the gamma-aminobutyric acid type A receptor is determined by a single amino acid in the beta 2 and beta 3 subunit. Proc Natl Acad Sci USA 91: 4569-4573.

Wu J, Harata N, Akaike N (1996). Potentiation by sevoflurane of the gamma-aminobutyric acid-induced chloride current in acutely dissociated CA1 pyramidal neurones from rat hippocampus. Br J Pharmacol 119: 1013-1021.

\section{Supporting information}

Additional Supporting Information may be found in the online version of this article:

Figure S1 $\mathrm{GABA}_{\mathrm{A}}$ receptor-mediated currents in hippocampal CA1 pyramidal and ventrobasal thalamic neurones. (A) Example of the current traces evoked by various concentrations of GABA in the hippocampal CA1 pyramidal neurone. (B) Example of the current traces of GABA-induced current in ventrobasal thalamic neurone. (C) THIP-induced currents in ventrobasal thalamic neurone. (D) Concentration-response relationship for GABA and THIP $(n=6)$. Data are fitted to the Hill equation

Figure S2 Potentiations of GABA-elicited currents induced by Rc-OMe is not voltage dependent. (A) Left, examples of current traces showing the potentiation of GABA-elicited currents $(1 \mu \mathrm{M})$ by Rc-OMe $(10 \mu \mathrm{M})$ at $+60 \mathrm{mV}$ and $-60 \mathrm{mV}$ at recombinant $\alpha_{1} \beta_{2} \gamma_{2 s}$ receptors expressed in HEK-293 cells. Right, I-V curve for GABA-elicited currents $(1 \mu \mathrm{M})$ in the absence and presence of Rc-OMe $(n=3)$. (B) Left, representative current traces with voltage ramps from a $V_{H}$ of $-65 \mathrm{mV}$ to $+15 \mathrm{mV}$ for $0.5 \mathrm{~s}$ in the absence and presence of Rc-Br $(3 \mu \mathrm{M})$. Right, baseline-subtracted current-voltage curves for the GABA-induced current shown in the left $(n=7)$.

Figure S3 Representive traces showing the potentiation induced by Rc-OMe of current elicited by $0.1 \mu \mathrm{M}$ THIP in VB thalamic neurones. The-all-points distribution was fitted by the sum of two Gaussians, and the peak of these fits was used to estimate current amplitude.

Please note: Wiley-Blackwell are not responsible for the content or functionality of any supporting materials supplied by the authors. Any queries (other than missing material) should be directed to the corresponding author for the article. 